Revue des patrimoines

$17 \mid 2011$

Les patrimoines de l'enseignement supérieur

\title{
La fa(r)ce cachée des Grandes Écoles : les « catacombes » offertes à leurs élèves!
}

\section{Gilles Thomas}

\section{(2) OpenEdition}

1 Journals

Édition électronique

URL : https://journals.openedition.org/insitu/1213

DOI : 10.4000/insitu.1213

ISSN : 1630-7305

Éditeur

Ministère de la Culture

Référence électronique

Gilles Thomas, "La fa(r)ce cachée des Grandes Écoles : les « catacombes » offertes à leurs élèves! », In Situ [En ligne], 17 | 2011, mis en ligne le 26 janvier 2012, consulté le 21 septembre 2021. URL : http:// journals.openedition.org/insitu/1213; DOI : https://doi.org/10.4000/insitu.1213

Ce document a été généré automatiquement le 21 septembre 2021.

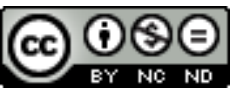

In Situ Revues des patrimoines est mis à disposition selon les termes de la licence Creative Commons Attribution - Pas d'Utilisation Commerciale - Pas de Modification 4.0 International. 


\title{
La fa(r)ce cachée des Grandes Écoles : les «catacombes » offertes à leurs élèves!
}

\author{
Gilles Thomas
}

« Vous savez que j'aime les voyages excentriques, les entreprises hardies, et que si, par hasard, il me prend envie d'écrire un volume, je n'en puise point

les matériaux dans les rayons de la Bibliothèque impériale : je vais à la source première, - la Nature,

- je vois, j'étudie, je raconte mes impressions. Ce n'est pas le cigare aux lèvres, les pieds sur mes chenets, que j'ai recueilli ces notes ; c'est le crayon

à la main, assis sur une pierre, dans les profondeurs silencieuses des voies qui sillonnent le sol de Paris.

[...] Suivez-moi, mon cher ami, je possède le peloton de fil d'Ariane, et ma main ne cessera de presser la vôtre »; (Les catacombes de Paris, de

Pierre-Léonce Imbert).

\section{Introduction}

1 Entre ${ }^{12}$ la Description des catacombes de Paris écrite par Héricart de Thury en 1815, premier ouvrage de vulgarisation consacré au sous-sol parisien (fig. $\mathbf{n}^{\circ} \mathbf{1}$ ), et Paris souterrain d'Émile Gérards paru en 1908, un seul écrit relatera en témoin direct la fréquentation " clandestine ${ }^{3}$ de ce lieu à nul autre pareil (et pas seulement parce que sous la ville) : Les catacombes de Paris de Pierre-Léonce Imbert ${ }^{4}$. Parmi les nombreuses promenades sous la capitale qu'il avait l'habitude de faire, il choisit de décrire un périple particulier avec forces détails. Cette promenade retenue et ainsi offerte à la curiosité des lecteurs, avait 
été effectuée en compagnie de cinq autres personnes : le jeune statuaire Claude Cochey ${ }^{5}$, Mounet-Sully sociétaire de la Comédie-Française ${ }^{6}$, un botaniste (muni d'un thermomètre) et (déjà) deux touristes.

Figure 1

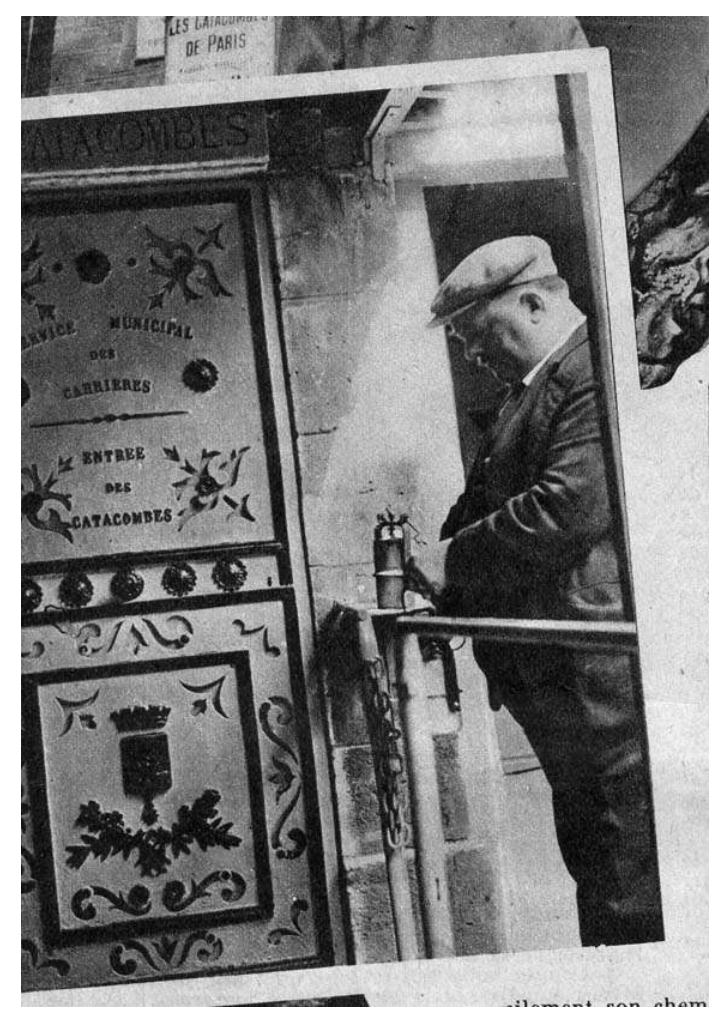

Ancienne entrée des Catacombes, datant de l'époque où celle-ci était située au fond de la cour du pavillon occidental de la Barrière Denfert (photo extraite du reportage paru sous la signature de LéonPaul Fargue dans « Voilà, l'hebdomadaire du reportage », n³31, 23 juillet 1937). L'entrée se faisait alors à 14 heures précises, le prix était de 3 francs, et comme nous étions en période d'Exposition Universelle la visite était possible tous les samedis.

Collection particulière.

2 Depuis, si d'autres ouvrages parurent, de manière cyclique en fonction des modes, aucune autre étude ne prit en compte la période contemporaine de son écriture et ne décrivit cette fréquentation du lieu par des amateurs attirés pour différentes raisons. Ainsi, lorsque l'on se plonge dans les essais et autres ouvrages de vulgarisation sur les carrières de Paris ${ }^{7}$, pour la majorité parus à la charnière des années 50's - 60's, ils ne sont généralement qu'un digest de celui de leur prédécesseur Émile Gérards, se contentant de décrire les lieux en faisant abstraction de sa population allogène. Aucun historien diplômé de la faculté, même traitant de la période contemporaine, ne semble vouloir s'y intéresser et considérer cette activité avec son regard universitaire. Espérons simplement avec cette modeste étude, ouvrir une brèche, et ne pas avoir à la maintenir trop longtemps entrebâillée du pied pour que quelqu'un ou quelqu'une s'y engouffre, afin que l'« Histoire moderne » ne soit pas le parent pauvre des études historiques.

3 Comme il sied à toute règle, la publication de Barbara Glowczewski, en 1983, semble être la seule à y faire exception ${ }^{8}$, mais parce que c'est le sujet revendiqué de son étude, jusque dans son titre, qui fait des sous-sols "catacombesques» de la capitale un autre Paris, peuplé d'une population de transit, contrairement au peuple des Talpa créé par Gaston 
Leroux $^{9}$; cette chercheuse en ethnologie surfant sur la vague naissante de cette mode ${ }^{10}$, ne traite d'ailleurs que de ce phénomène de la fréquentation des carrières de Paris par les individus qu'une néonymie récente dénomme "cataphiles». Sa réédition associative récente, en 2008, laissait entrevoir un espoir de réactualisation, mais il n'y fut simplement ajouté qu'une annexe, déjà présente dans le mémoire originel. Les nombreux autres mémoires d'études dont nous avons eu connaissance, quel que soit le niveau (école polytechnique, d'ingénieurs - de la Ville de Paris ou autres -, grandes écoles telles que HEC, mémoires universitaires de maîtrise, DEA, mais rarement thèse, etc. ${ }^{11}$ ) ne semblent que des alibis pour pouvoir justifier de descendre et se donner bonne conscience auprès de crédules autorités.

Pourtant, s'il semble possible a posteriori de tenter de tels rassemblements d'informations, travail incommensurable mais irremplaçable, rien ne vaut le recueil de souvenirs de témoins directs, bien qu'assurément entachés d'erreurs et de déformations involontaires. "Notre mémoire vit sa vie propre à mesure que nous avançons en âge. Tandis qu'elle s'exerce sur nos souvenirs du passé, nous ne la surveillons point ; elle a ses caprices, ses erreurs d'optique, ses défaillances. Telle trace topographique s'efface totalement; telle autre se confond avec une plus récente. Tous les souvenirs écrits des gens célèbres sont plein de graves erreurs de lieux et de dates, pour la torture et pour la joie des commentateurs. Que de fois, bien que pourvu moi-même d'une mémoire mieux que moyenne, j'ai fait l'épreuve de son infidélité : trahison serait même le mot, car au lieu d'avouer: "je ne me rappelle pas" notre mémoire nous présente des mirages avec la même assurance que des réalités ", nous prévient Marcel Prévost, Polytechnicien (X1882), et académicien ${ }^{12}$.

\section{Paris souterrain : des carrières d'extraction au réseau des « catacombes »}

\section{Au sujet des Catacombes : de l'utilisation du mot et de la chose}

5 C'est à la découverte d'un usage récurrent, au sein des Grandes Écoles parisiennes, des anciennes carrières souterraines de la Ville de Paris, dénommées « catacombes » par abus de langage, que vous convie ce memorandum. Par cette fréquentation éminemment scolaire, aujourd'hui définitivement abandonnée, ce sont des milliers de personnes qui découvrirent ces fabuleux et féeriques espaces souterrains, et y revinrent parfois indépendamment de tout encadrement formel.

6 Ce mésemploi du terme de catacombes se comprend parfaitement sachant que dès 1782, soit quatre années avant la création de la chose sous la capitale, un opuscule anonyme était en vente dans les magasins de nouveauté stipulant déjà que l'on allait créer des Catacombes à Paris ${ }^{13}$, ceci par analogie avec les fameuses Catacombes de Rome alors à la mode. De l'espace des anciennes carrières souterraines de la ville réservé pour le transfert des ossements des cimetières parisiens, à l'ensemble des galeries situées sous Paris, on conçoit que par synecdoque métonymique le nom adopté pour l'ossuaire municipal soit devenu celui du réseau général baptisé de nos jours Grand Réseau Sud (GRS) <lien vers http://geos1777.free.fr>, pour le distinguer des autres réseaux de carrières parcourables sous Paris. Par association d'idées, "catacombes » a de suite été dévoyé pour les autres réseaux de galeries de carrières parisiennes, qu'ils soient également de calcaire comme le GRS mais indépendants, ou de gypse comme ceux des 
buttes géologiques témoins du Nord de Paris (Montmartre, Buttes-Chaumont) <lien vers http://www.annales.org/archives/carrieres.html>. Par exemple, au XIX siècle, des scientifiques adoptent ce raccourci simplificateur pour désigner les salles aménagées dans les carrières sous le Muséum d'Histoire Naturelle de Paris à des fins d'étude sur l'évolution (c'est « le laboratoire des catacombes du jardin des Plantes»). Ou bien, lors de l'Exposition universelle de 1900, deux animations souterraines sont organisées dans les " catacombes du Trocadéro $»^{14}:$ l'Exposition minière souterraine, et le Monde souterrain.

Puis un glissement sémantique se fit jour, qui utilisa catacombes pour désigner ce qui est non seulement noir, obscur, mais aussi ce qui est vide, caché, creux ou tout simplement tu. C'est ainsi que l'on va par exemple parler de la république des Catacombes ${ }^{15}$, des catacombes de l'Histoire, des catacombes de l'humanité, des catacombes de l'esprit ${ }^{16}$, des catacombes de la détresse, des catacombes de l'imaginaire ${ }^{17}$ ), ou que fut vendu tout récemment l'essai «Petit monarque et catacombes », par Olivier Maulin ${ }^{18}$.

Dès l'origine de la chose, avant celle du mot, ces lieux souterrains ont été hantés par une population curieuse, ou avide de détourner à leur profit l'espace souterrain malfamé pour des activités que l'on pourrait penser frauduleuses. Divers écrits nous relatent ces faits qui parfois remontent au moyen-âge (les manifestations du diable dans les sous-sols du château de Vauvert ${ }^{19}$ ), mais par un phénomène de contraction du temps la période la plus récente est la moins bien connue par manque d'archives ${ }^{20}$, personne ne pensant à garder des documents et à faire une synthèse de ce qui existe ${ }^{21}$. Ainsi on lit, daté du 9 mai 1777 déjà, sous la plume d'Antoine Dupont, professeur de mathématique de son état et ayant pour cette raison cartographié quelques carrières souterraines, alors qu'il informe par lettre le sieur Guillaumot (premier « Inspecteur général des carrières sous Paris et plaines adjacentes » en titre) : « Nous avons des gens qui viennent la nuit et font des fêtes dans nos carrières. Ils nous débouchent les puits. J'ai le nom de trois et la demeure de deux que je viens de donner à $\mathrm{Mr}$ le lieutenant de police $»^{22}$.

9 C'est ainsi que continuent d'être colportés au sujet des sous-sols de la capitale, lieux communs et légendes urbaines, en un mot des fantasmes populaires entretenus par des journalistes en mal de sensations, relayés parfois par des docteurs en histoire qui ne se donnent pas la peine d'aller voir sur le terrain, d'autant plus quand il est souterrain; voudraient-ils faire croire que les "catacombes de Paris" sont des endroits où se réunissent des groupuscules politiques ${ }^{23}$, des sociétés secrètes, des sectes, voire des usagers de drogues, etc. ${ }^{24}$, qu'ils ne s'y prendraient pas autrement !

\section{De la genèse des carrières souterraines à la vocation d'une carrière professionnelle}

10 Dès l'époque gallo-romaine, Paris exploita les richesses de son sous-sol à ciel ouvert, mais il faudra attendre l'élévation d'églises au Moyen Âge pour qu'en un mouvement symétrique et antagoniste, des hommes s'enfoncent dans les entrailles de la terre pour en extraire les racines architecturales de ces monuments cultuels. Ce n'est en effet qu'à partir de la fin du XII ${ }^{e}$ - début du XIII ${ }^{e}$ siècle qu'apparurent les premières carrières souterraines. Louis Sébastien Mercier décrit ainsi la situation dans son Tableau de Paris (1781) «tout ce qu'on voit en-dehors, manque essentiellement dans la terre aux fondements de la ville»; ce qui, traduit dans un langage plus populaire par Rondin ${ }^{25}$ donnera : "Pour construire les maisons au-dessus, ils ont pris les pierres en dessous». Après la formation en 1776 d'une «cellule préfigurative » en la personne d'Antoine 
Dupont, le 4 avril 1777 fut finalement créée l'Inspection des carrières (IDC) (fig. $\mathbf{n}^{\circ} \mathbf{2}$ ), service chargé de répertorier, cartographier et consolider les fondations cariées de la ville capitale, aux fins d'obvier à ce que les collines parisiennes "ne fissent la révérence ", entraînant pêle-mêle hommes, bêtes et bâti.

Figure 2

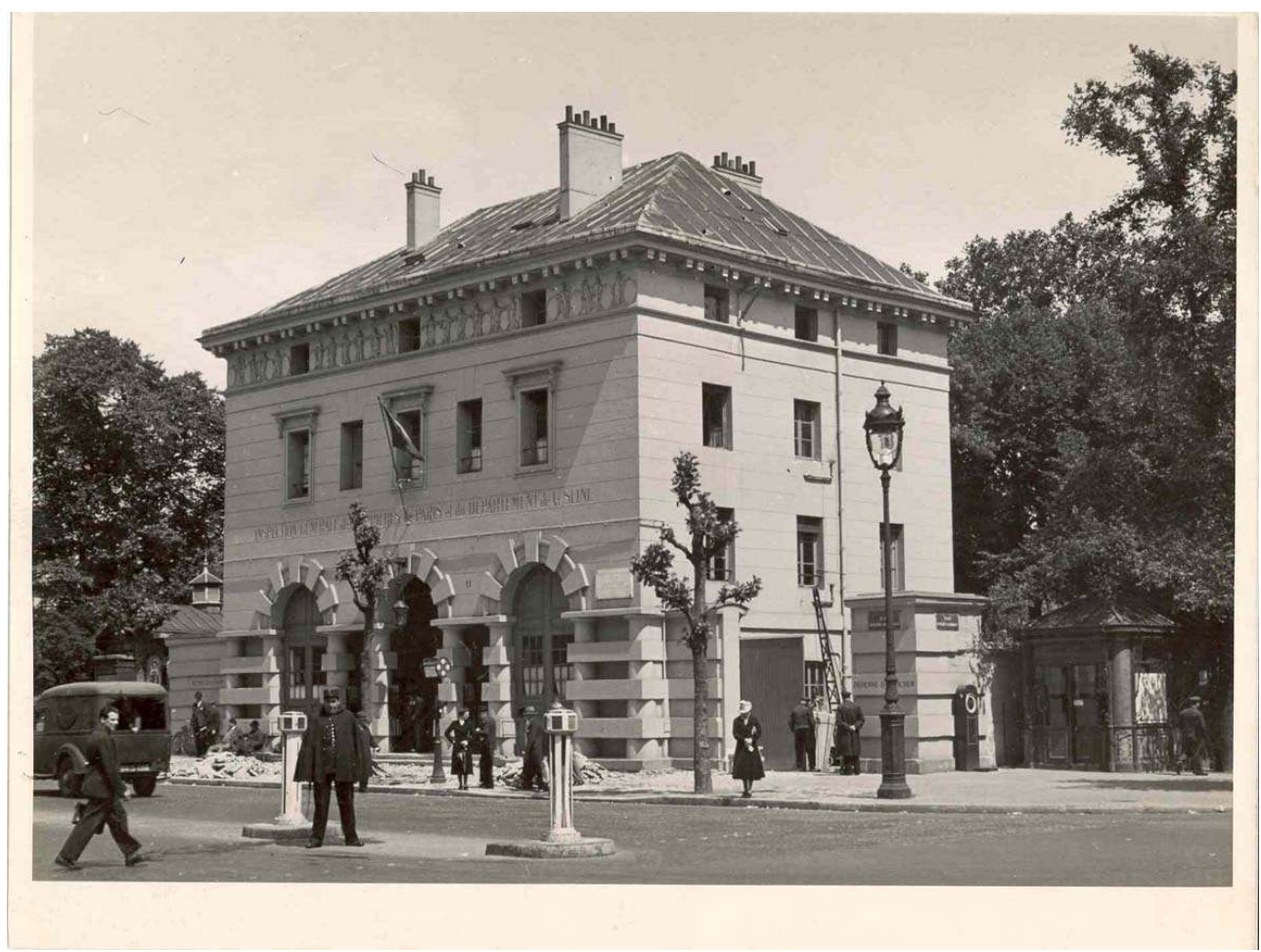

Pavillon oriental de la barrière d'octroi dévolu à l'Inspection des carrières succédant ainsi, lors de la prolongation du chemin de fer de Sceaux dans Paris, à la caserne de gardes républicains à cheval qui l'occupait depuis 1860. Sur cette photo exceptionnelle se lit, juste au-dessous des fenêtres du deuxième étage (côté place), « Inspection générale des carrières de Paris et du département de la Seine » ; l'inscription a aujourd'hui disparu.

Collection particulière.

11 La méthode employée consista à édifier de gros piliers maçonnés à l'aplomb des murs porteurs des bâtiments édifiés sur le vide d'anciennes carrières par simple méconnaissance des excavations présentes. Étant donné que dans les rues parisiennes les habitations ont tendance à être relativement alignées et à se faire face sur les deux côtés de la voirie, les massifs de maçonnerie souterrains suivent le même profil, ce qui génère deux parements linéaires en vis-à-vis délimitant un couloir souterrain. C'est l'ensemble de ce réseau de galeries de servitude que l'on désigne par la dénomination de « anciennes carrières souterraines de la ville de Paris ", ce qui, par ellipse, donne les "Carrières de Paris », détournées en $"$ catacombes $»^{26}$, et qui constitue donc de nos jours la « doublure topographique du Paris du siècle des Lumières ».

12 Hormis le personnel y travaillant, de très nombreux individus eurent à connaître les galeries de ces anciennes carrières sous Paris : artistes, littérateurs, étudiants, chacun, quelle que soit sa connaissance des lieux, en retint la «balade interdite dans les catacombes », pour reprendre le titre de l'exposition «La doublure de Paris » organisée par le ministère de la Culture pour les légations françaises à l'étranger (elle circula dans 
50 Alliances françaises, depuis la parution de la «Cité des Cataphiles» jusqu'en 1992), suite à l'étude de Barbara Glowczewski.

Par exemple, pour l'École Normale Supérieure, la période de fréquentation assidue des carrières par les élèves cessa à la fin des années 60's. Une note de Jean Deprun (L1943) évoque du reste le "sol miné, affaissé, que suce la bouche des Catacombes ; portes ouvertes sur d'imprécis ossuaires, étalez sans crainte vos délices $»^{27}$ (fig. $\mathbf{n}^{\circ} \mathbf{3}$ ). Les Normaliens possédaient une autre activité considérée à juste titre comme un loisir incontournable par ses adeptes : l'escalade des toits de l'École. On peut ainsi dire qu'ils embrassaient Paris de "fond en combles», ou qu'ils étaient des explorateurs des «Catacombles ».

Figure 3

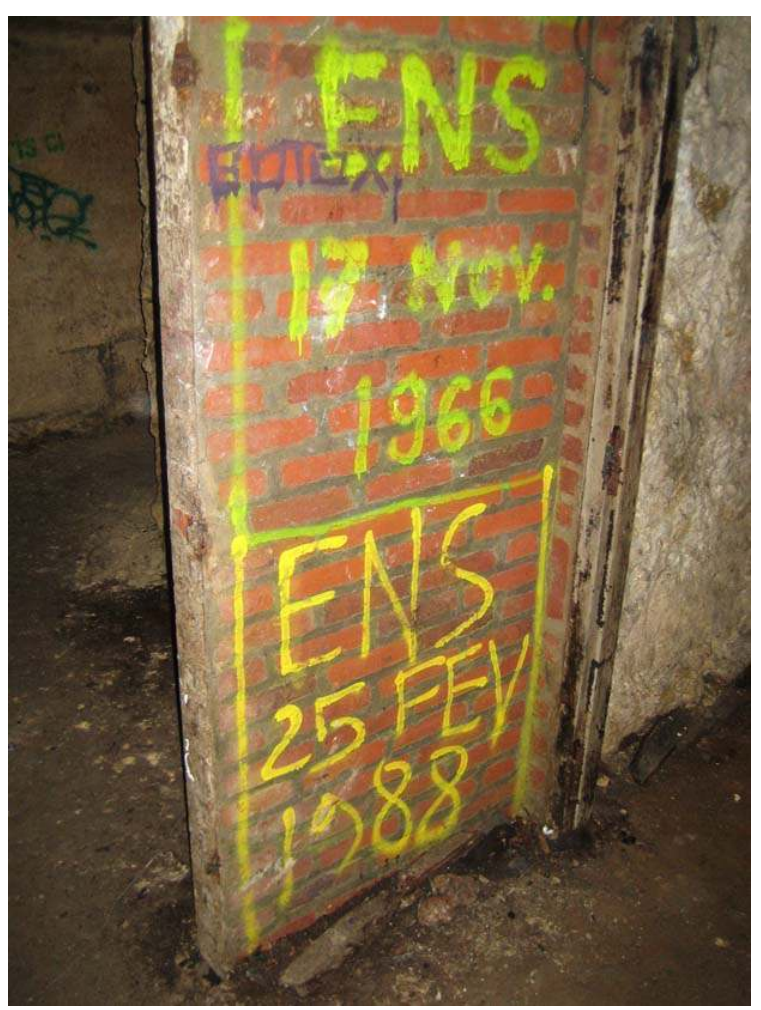

Sur cette paroi en brique d'un abri de la seconde guerre mondiale aménagé au niveau des carrières souterraines, on voit, par l'inscription à la peinture qu'ils y ont laissée, que des élèves de l'École Normale Supérieure sont passés en 1966. Vingt-deux années plus tard, d'autres Normaliens mirent leurs pas dans les empreintes de leurs prédécesseurs, compte non-tenu des élèves de toutes les promotions intermédiaires qui visitèrent les carrières de Paris sans pour autant laisser de traces. (C)Tillier, Sylvain.

Concernant l'École Polytechnique, André Giraud, ancien Ministre, déclara au cours d'une interview accordée à un newsmagazine ${ }^{28}$ concernant ses « racines chahuteuses » que : « Major, il n'est pourtant pas le dernier à inventer des canulars et animer les chahuts de l'X. Avec ses amis Pierre Laffitte (aujourd'hui sénateur), il participe aux escapades nocturnes et aux "gueuletons" dans les souterrains de Paris $»^{29}$. De plus, il semblerait qu'une des traditions à Polytechnique ait consisté à ce que les nouveaux descendent au moins une fois dans les « égouts » (qu'il convient d'interpréter par les carrières ${ }^{30}$, les regards d'accès étant fortement similaires pour ne pas dire identiques aux yeux du vulgum pecus ; ils sont également parfois dénommés «tampon d'égout » par abus de langage !) et en ramènent 
une plaque de rue, comme trace de réussite de leur épreuve de rite de passage et d'intégration.

\section{De l'étudiant en topographie au cataphile passionné}

\section{En partant d'un bon sentiment, on fit entrer le loup dans la bergerie}

Dès la création du réseau architecturé que nous connaissons encore de nos jours au sein des anciennes carrières souterraines, i.e. à la fin du XVIII ${ }^{e}$ siècle, les élèves de l'École polytechnique furent conviés à venir observer et étudier les gigantesques travaux d'urbanisme alors entrepris sous la capitale. C'est Charles-Axel Guillaumot qui eut l'idée de faire connaître les portes d'accès de ces galeries parisiennes à la curiosité estudiantine, ouvrant par là-même une boîte de pandore dont le couvercle ne se referma jamais, ou selon une métaphore plus cinématographique « les rats sont dans le fromage $»^{31}$. La vision des confortations souterraines réalisées par l'IDC, indispensables pour éviter que la capitale ne s'écroule dans ses propres entrailles, fut donc proposée à l'œil malicieux des Polytechniciens.

16 Ainsi le 22 floréal an 6 (11 mai 1798), Guillaumot écrivit au ministre de l'intérieur: "Citoyen ministre, je ne vois aucun inconvénient à ce que les élèves de l'école polytechnique prennent connaissance des travaux qui se font pour le soutènement des carrières sous Paris. J'y vois au contraire pour moi l'avantage de les soumettre au jugement des instituteurs éclairés de cette école, et de profiter de leur avis, ou d'être honoré de leur approbation. Je vais, en conséquence, concerter avec ces instituteurs et avec le directeur de cet établissement important, le jour où nous pourrons en faire la visite » (fig. $\left.\mathbf{n}^{\circ} \mathbf{4}\right)$. Ce n'était pas vraiment une première d'ailleurs puisque, par une lettre du $1^{\mathrm{er}}$ mars 1778 dans laquelle Guillaumot écrit ses réflexions sur la conduite de Dupont, on apprend que ce dernier aurait "osé paraitre dans les carrières avec ses élèves", formulation manifestant une animosité certaine entre ces deux individus! Et cette vocation pédagogique des carrières sous Paris perdurera jusqu'au tout début du $\mathrm{XX}^{\mathrm{e}}$ siècle 32 . 
Figure 4

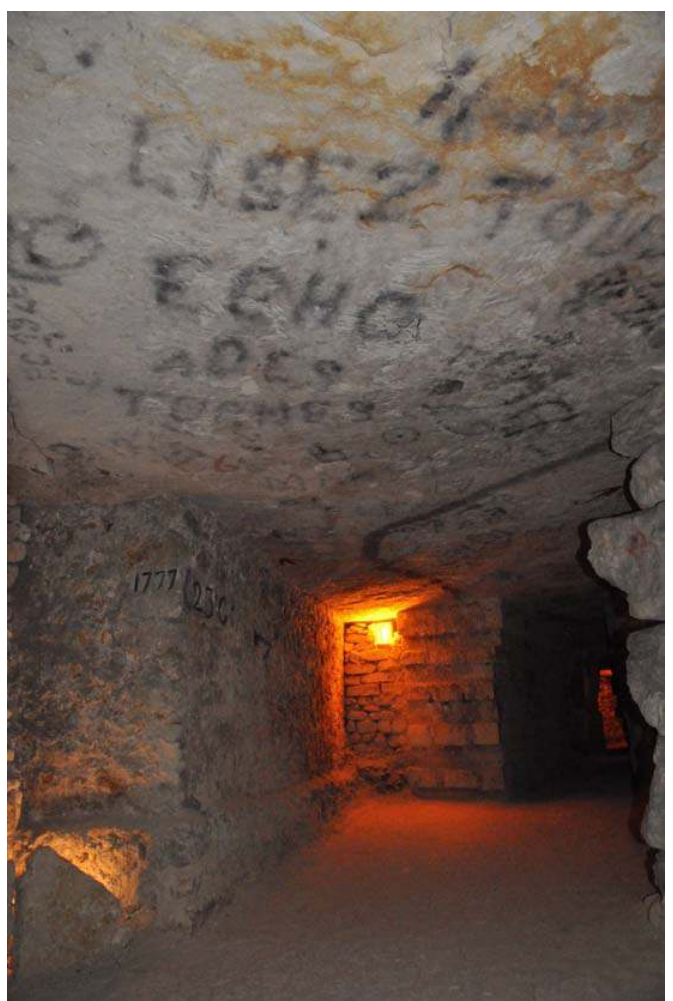

Exemple de consolidation due à Charles-Axel Guillaumot en 1777, soit l'année même de création de I'Inspection des carrières. Le pilier est numéroté pour des raisons d'identification selon la codification trinômiale classique i.e. « Numéro d'ordre » «Initiale de l'Inspecteur général en chef à la tête du service » «Année de réalisation »; ici « 23 G 1777 ». Au ciel se lit l'inscription au noir de fumée « Lisez tous l'Écho des Turnes », exhortation écrite par des élèves de l'École Centrale de Paris entre 1900 et 1937, ce journal étant alors leur revue interne.

(c) Pogodalla, Anne, 2010.

17 Les Grandes Écoles étant des lieux relativement clos et dans lesquels se cultive le corporatisme, elles ne sont pas pour autant totalement cloisonnées les unes par rapport aux autres. C'est ainsi que, pour se limiter à celles ayant été le plus impliquées dans la fréquentation souterraine des « catacombes » de Paris, on peut citer les Mines, (du milieu du XIXe siècle jusqu'à la seconde moitié du XXe), puis l'école Centrale (au moins de 1893 à 1937), l'école supérieure de géomètres et topographes (ou SupGéTo, de sa création en 1946 au sein du Cnam, à sa première délocalisation ${ }^{33}$ ), les Ponts \& Chaussées, les Arts et Métiers, énumération à laquelle nous ajouterons l'école des Beaux-Arts ; sans pour autant négliger tous les internes en médecine dont «le chemin de l'Internat passait par les Catacombes $»^{34}$. Il ne faut donc pas s'étonner si, la porte ayant été entrouverte pour y laisser passer les Mineurs, les autres Grandes Écoles s'engouffrèrent dans la brèche, et utilisèrent ces lieux comme site pratique pour l'entraînement et la réalisation des exercices topographiques inclus dans leur cursus scolaire; mais des élèves y allèrent également par simple plaisir de la découverte et de l'aventure à peu de frais, et surtout à portée de main car au pas de la porte ${ }^{35}$. De nos jours la seule Grande École ayant maintenu une telle tradition underground est celle des Mines, qui est aussi pour l'instant, l'une des rares à ne pas avoir été délocalisée. Mais aucune étanchéité n'est bien évidemment véritablement établie entres les différentes écoles, outre les professeurs pouvant officier dans plusieurs écoles, les élèves se rencontrent au cours d'activités en commun (ne serait- 
ce que lors des rencontres sportives comme le Challenge inter Grandes Écoles), il y a par exemple toujours des Polytechniciens ou des élèves des Ponts \& Chaussées qui descendent sous Paris seuls ou guidés par des élèves des Mines.

Figure 5

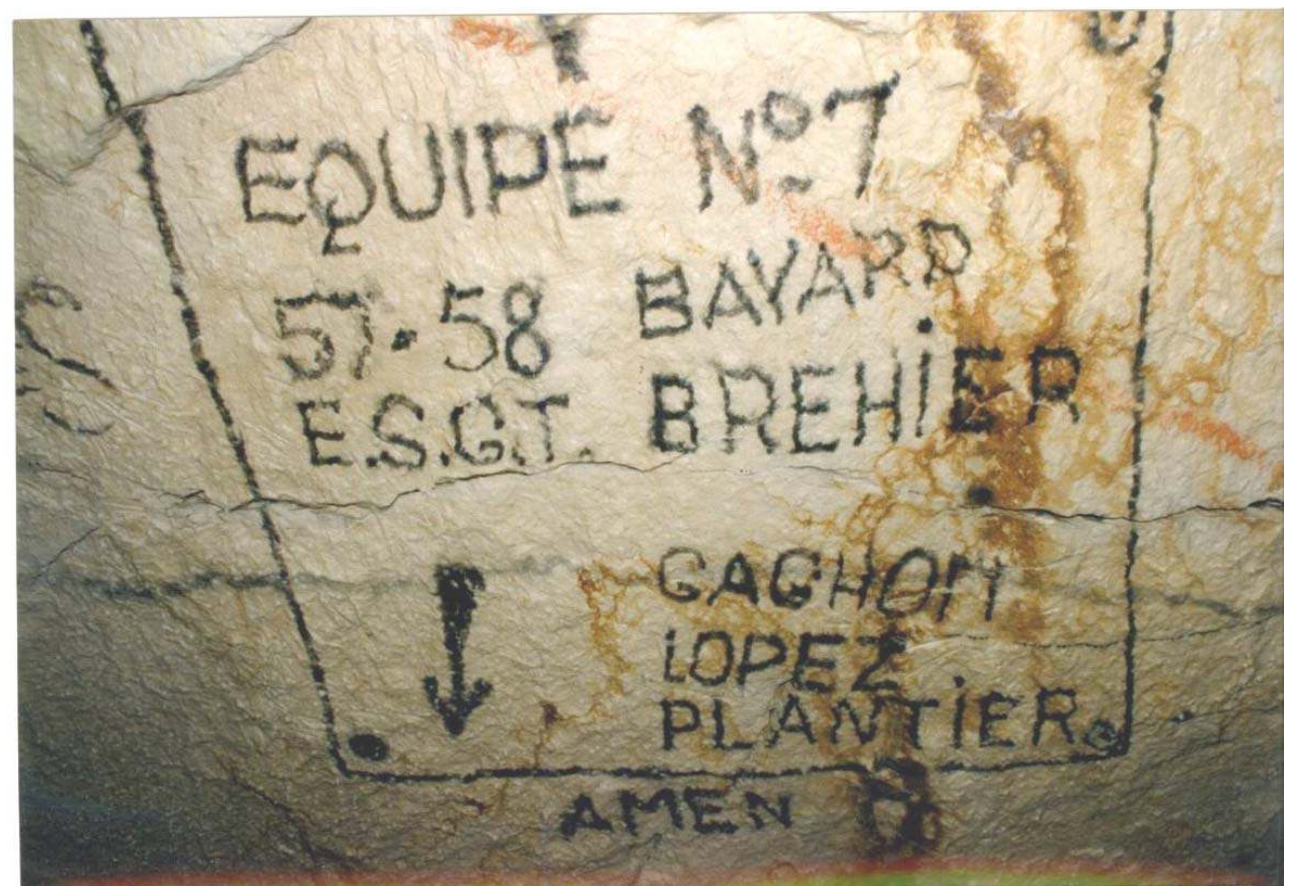

En ciel de carrière dans le secteur Cochin - Val-de-Grâce, se trouvent de très nombreuses inscriptions liées aux travaux pratiques de SupGéTo, l'École Supérieure de Géomètres et Topographes. Ici tout simplement la liste des élèves du groupe numéro 7 (des années 1957-1958) qui s'initia à la topographie souterraine.

(c) Largier, Jean-Luc, 1995. 


\section{Figure 6}

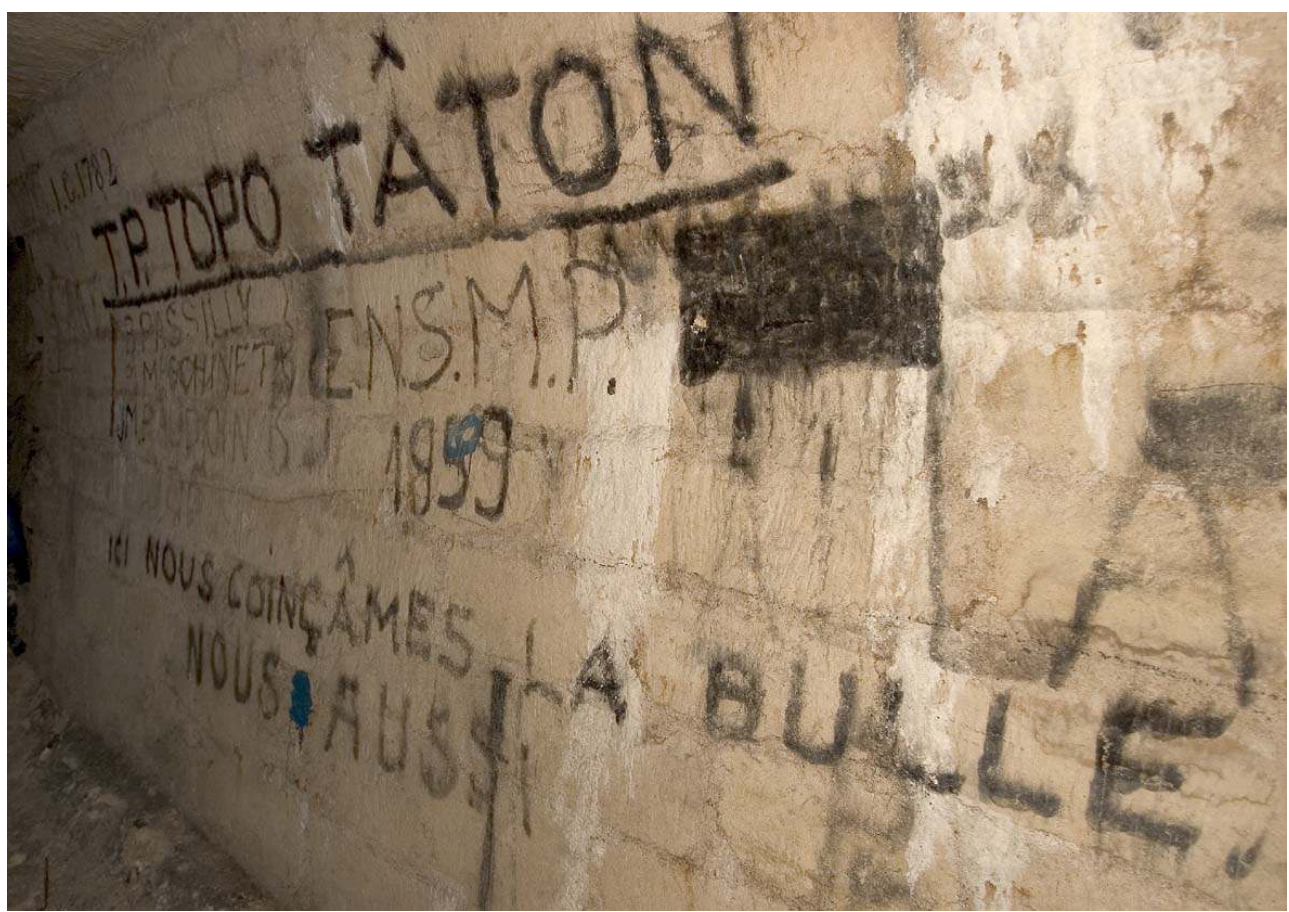

En 1959, des élèves de l'École des Mines « coincèrent la bulle » sous Paris, ce que l'on peut interpréter des deux façons : réglèrent leur appareil de topographie, mais aussi prirent du « bon temps ». Leur professeur Robert Taton (enseignant à l'École Nationale Supérieure des Mines à partir de 1945, à l'École Supérieure de Géomètres et Topographes, et à l'Institut de Topométrie du CNAM), outre qu'il laissa son nom à un manuel de "Topographie souterraine », édité par Eyrolles en 1960, vécut une mésaventure souterraine qui le marqua plus que de raison et qu'il raconta sous le titre « La nuit la plus longue » («Les entrailles de Paris ». Géomètre, octobre 1973, octobre p. 19-29). Ses élèves ne purent s'empêcher à la suite de cette anecdote d'écrire à divers endroits des carrières "À poil et à Taton », puisqu'il faillit finir ainsi sous terre, et une scie circulait à SupGéTo : « Comment fait-on de la Topo Sout'? à Taton! ».

(c) Albaret, Franck. 
Figure 7

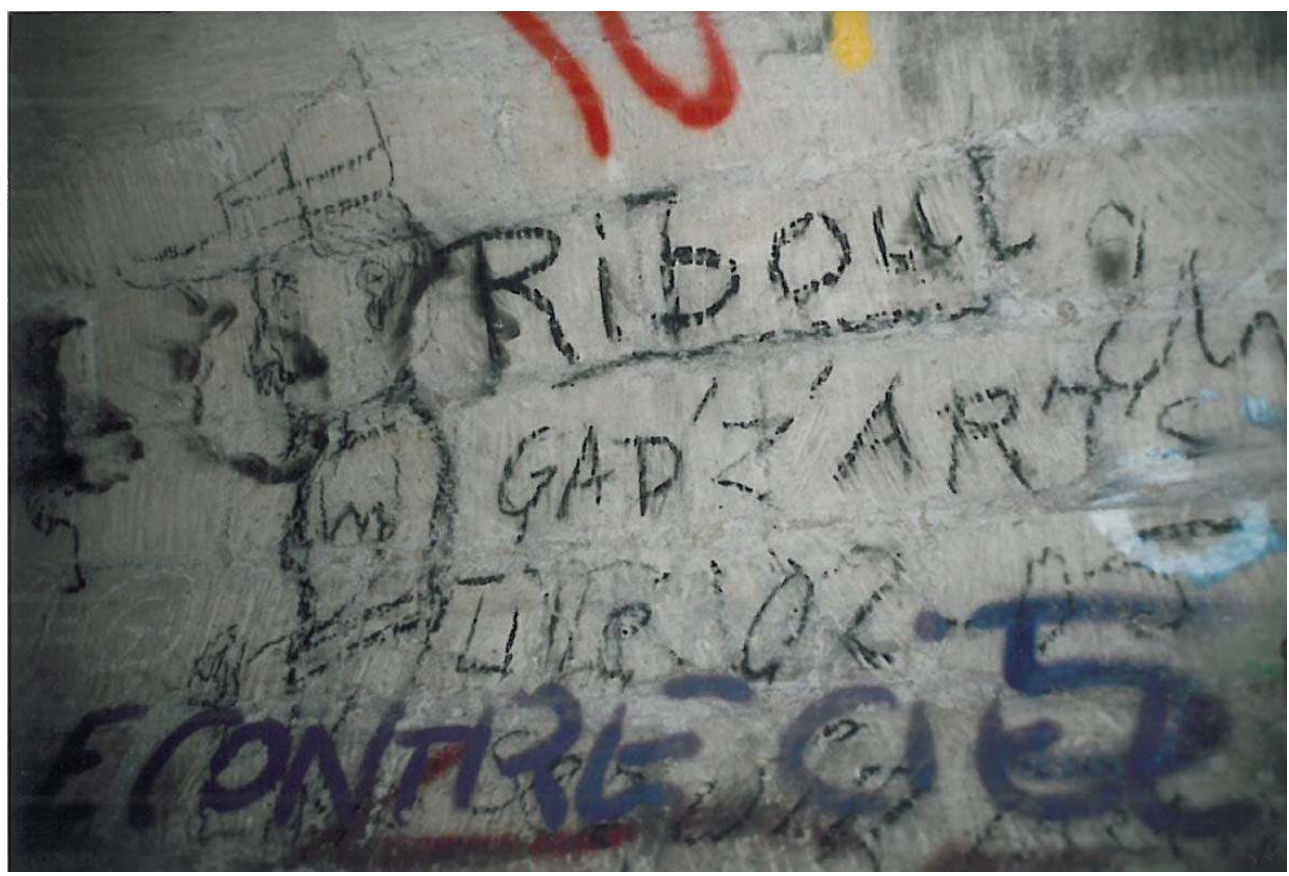

Des élèves de l'École des Arts et Métiers sont eux-aussi allés « s'encanailler » dans les carrières sous Paris, mais on ne trouve in situ que très peu de preuves de leur passage. II y avait au moins celle-ci, encore visible il y a quelques années, mais qui a été depuis irrémédiablement tagguée.

(c) Legrand, Jean-Yves, 1994. 
Figure 8

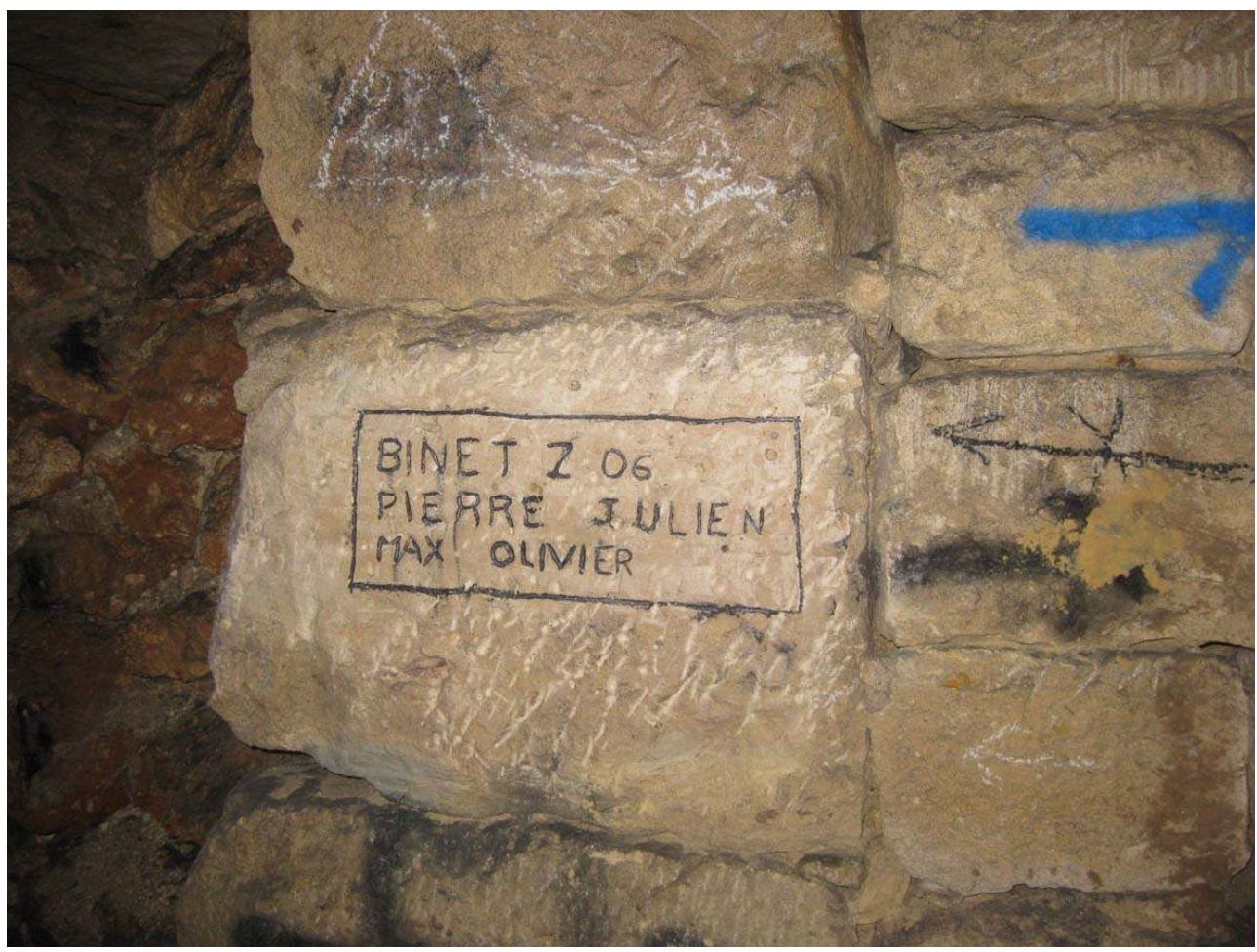

Trace actuelle de passage de deux Polytechniciens de la promotion 2006, faisant partie du Binet Z. Un Binet dans l'argot de l'X est un cabinet, autrement dit un club, chacun étant spécialisé dans une activité sportive, culturelle, de loisir, etc., mais il suffit d'une seule personne pour former un binet.

(c) Deschamps, François C., 2009.

$18 \quad\left(\right.$ fig. $\left.n^{\circ} 5\right)\left(\right.$ fig. $\left.n^{\circ} 6\right)\left(\right.$ fig. $\left.n^{\circ} 7\right)\left(\right.$ fig. $\left.n^{\circ} 8\right)$

19 En outre, on peut estimer qu'il y a toujours au moins un élève de chaque promotion des Mines pour laisser entrebâillé l'accès aux sous-sols catacombesques, le maintenant ainsi ouvert pour des relations triées sur le volet ${ }^{36}$. Des évocations de ces périples infraparisiens peuvent se retrouver dans des publications internes à l'École ${ }^{37}$, ce qui est un moindre mal, mais parfois la «fuite» est due à un élève qui en parle lui-même dans la presse $^{38}$; on n'est jamais si bien trahi que par les siens!

\section{Pourquoi et comment les Mineurs décidèrent-ils de faire « carrière »?}

20 L'École des Mines de Paris est située en plein quartier latin, mais au delà du sommet de la côte du boulevard Saint-Michel, ce qui la positionne exactement au dessus du banc de calcaire exploité autrefois pour l'édification de la capitale; elle possède en outre un escalier permettant de rejoindre directement le réseau des catacombes (fig. $\left.\mathbf{n}^{\circ} \mathbf{9}\right)$. Quoi donc de plus naturel que d'y organiser des exercices topographiques souterrains de manière à habituer ses élèves, alors futurs dépositaires de la gestion de concessions minières tant en France qu'à l'étranger, aux conditions particulières à la cartographie souterraine ${ }^{39}$ : absence de lumière, aspect labyrinthique, humidité ambiante, gabarit restreint des galeries, instruments et opérateurs soumis à des salissures permanentes, etc. Ces exercices, pour lesquels nous avons des traces dès le milieu du XIX ${ }^{e}$ siècle, se 
poursuivirent jusque vers le milieu des années 1960 du siècle suivant; les galeries souterraines parisiennes peuvent ainsi s'enorgueillir de plus d'un siècle de bons et loyaux services dans le cadre de la formation professionnelle de cette élite.

Figure 9

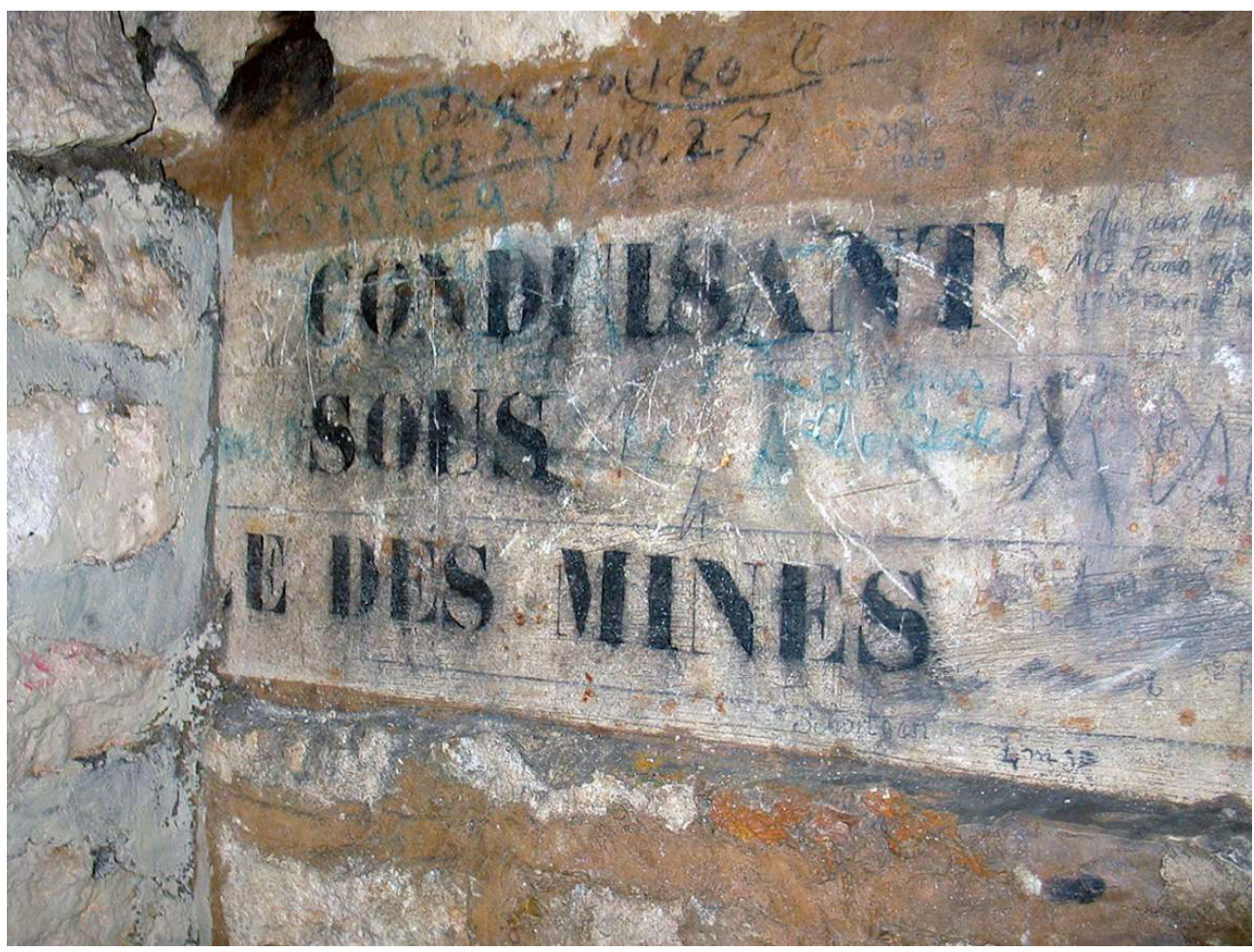

Inscription non pas gravée mais réalisée uniquement au pochoir, désignant la galerie menant autrefois sous l'École des Mines et libellée « [Chemin] conduisant sous [l'Écol]e des Mines ». Sur la plaque, un élève a écrit ses initiales MG, accompagnées du cri de ralliement de l'École : « Chic aux Mines ». On lit également au-dessus le nom de Robert Dormois, de l'École des Mines de Nancy (promotion N39) ; lors de la seconde guerre mondiale, les élèves de Nancy avaient été regroupés avec ceux de Paris.

(C) Baunau, 2009

21 Ces premiers exercices souterrains (jusqu'au tout début du XXe siècle) eurent lieu dans le secteur de la rue et du boulevard Saint-Jacques, puis se poursuivirent dans les anciennes carrières sous-minant l'hôpital militaire du Val-de-Grâce (fig. $\mathbf{n}^{\circ} \mathbf{1 0}$ ), jusqu'à l'abandon de cette formation au début des années soixante, suite à une réforme importante de l'enseignement. Sous terre, les élèves avaient pris pour habitude d'écrire leurs noms au crayon ou à l'aide d'une flamme nue, généralement sur les parois, mais parfois en ciel des galeries; c'est ainsi qu'il nous a été loisible, à partir du relevé de toutes ces traces méconnues laissées sous Paris, de reconstituer le tiers de tous les groupes formés pour les travaux pratiques (et autres exercices en commun) de l'école des Mines entre 1850 et 1900 $<$ http://www.annales.org/archives en regardant aux noms de chacun des élèves>. Cette proportion est fort honorable, une partie non négligeable du hiatus dans ce corpus des graffitis des Mineurs s'expliquant par les travaux d'établissement de la ligne $6 \mathrm{du}$ métropolitain ; la galerie sud du boulevard Saint-Jacques a en effet complètement disparu à cette occasion, détruite lors de la construction en 1901-1902 des consolidations de cette ligne numérotée alors 2-Sud (fig. $\mathbf{n}^{\circ} \mathbf{1 1}$ ). 


\section{Figure 10}

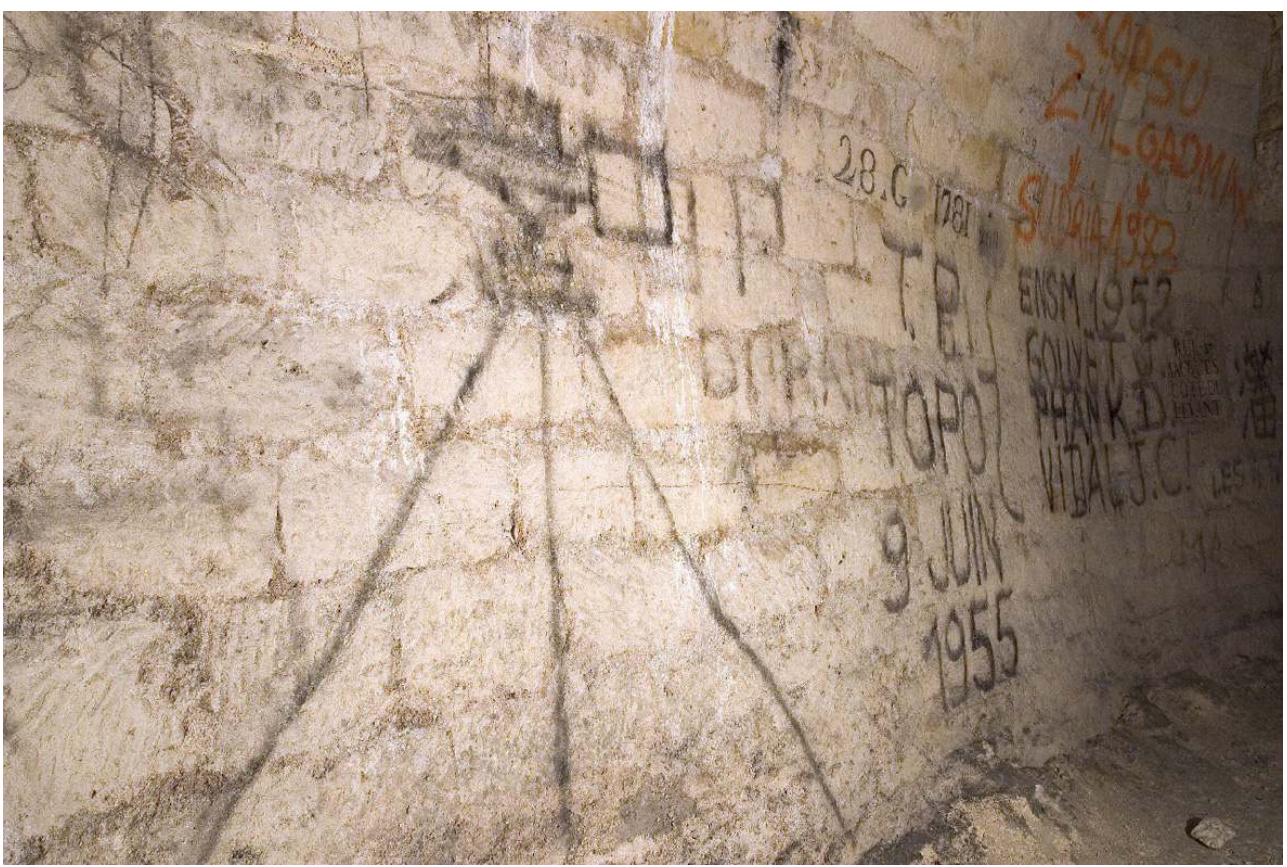

Dessin d'un niveau à lunette datant de 1955, année emblématique car le 2 novembre fut pris l'arrête interdisant à toute personne de pénétrer et circuler dans les anciennes carrières sous Paris sans autorisation. Cette représentation est due à un trinôme de TP de Topo de l'École des Mines qui officia dans les carrières « labyrinthiques » du Val-de-Grâce, offrant des paysages plus variés que les galeries « ordinaires » à l'aplomb des rues.

(c) Albaret, Franck. 
Figure 11

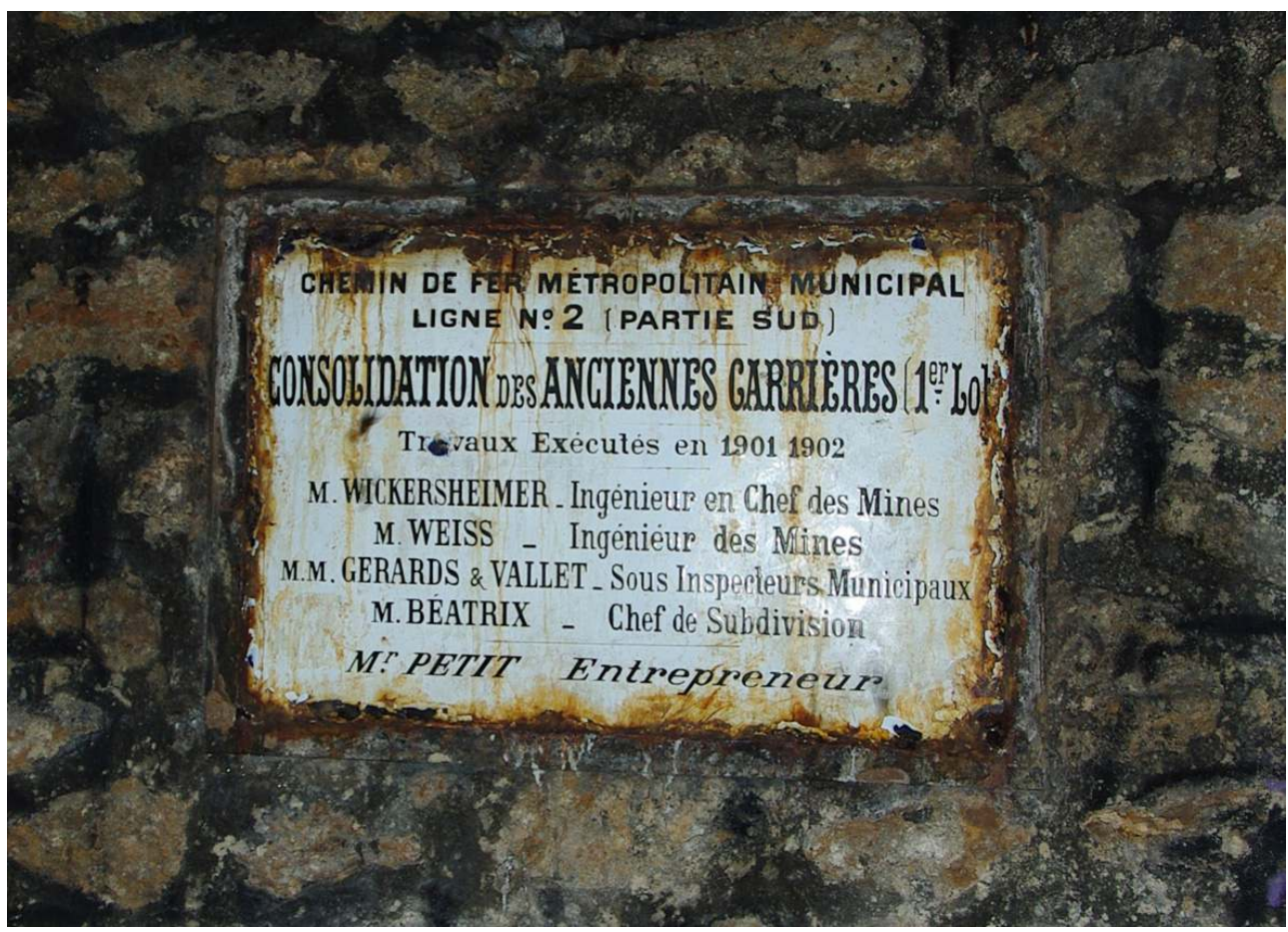

Lors des travaux de consolidation de la ligne de métro $n^{\circ} 6$ actuelle, la galerie de servitude de I'Inspection des carrières à l'aplomb du côté sud du boulevard St-Jacques fut entièrement détruite pour y édifier les piliers de soutien de la voie métropolitaine. Ceci fit disparaître les cartouches commémoratifs qu'avait dû y écrire chacune des brigades topographiques d'élèves de l'École des Mines, et qui devaient être aussi nombreux que ceux dont nous avons eu la chance de faire le relevé dans la galerie Nord toujours en place.

(C) Paris, Dominique, 2010

22 À l'origine, l'enseignement dans les Grandes Écoles d'ingénieurs possédait une composante militaire non négligeable: bien évidemment le rythme du travail, la discipline, les punitions, le port de l'uniforme (que l'on retrouve non seulement de nos jours à Polytechnique ${ }^{40}$, mais aussi à l'École Centrale - deux écoles dorénavant délocalisées dans la banlieue Ouest -, voire aux Arts et Métiers), l'initiation au déplacement en ordre serré, au maniement du fusil... Ce qui explique aussi, pour l'école des Mines, la dénomination de «Brigades» pour les groupes de travail, constitués d'élèves sous la responsabilité de l'un des leurs, le «Brigadier ${ }^{41}$, généralement un « Élève-Ingénieur », ce qui participait tacitement à sa formation car ils étaient destinés au recrutement du Corps des Mines.

Les exercices de lever de plans souterrains avaient lieu les mois d'été après la période des examens. L'enseignement théorique s'étant déroulé de mi-novembre à mi-mars, les dates que les brigades ont laissées sur les parois des galeries pendant leurs exercices correspondent à l'année d'entrée de leur promotion incrémentée d'une unité. Cette première visite des « catacombes ", si elle permettait la découverte d'un site insolite, était parfois l'occasion d'une révélation, d'une attirance pour certains élèves ${ }^{42}$, qui pouvait aussi se transformer en passion inextinguible. Ce que démontre le mathématicien illustre Henri Poincaré (Polytechnicien de la promotion 1875 des Mines), qui succomba lui aussi à la tentation ${ }^{43}$. Ce qui fut donc le cas de Poincaré, l'un de nos plus grands savants. Il écrivit à sa mère en juillet 1876: «Catacombes et catacombes, tels sont les événements 
principaux de ma vie depuis vendredi. Elles ont du moins cela de bon qu'il y fait très frais : j'y passe les heures les plus chaudes de la journée de midi à $5 \mathrm{~h}$ et je suis très étonné en remontant de trouver la température des tropiques $»^{44}\left(\right.$ fig. $\left.\mathbf{n}^{\circ} \mathbf{1 2}\right)$.

Figure 12

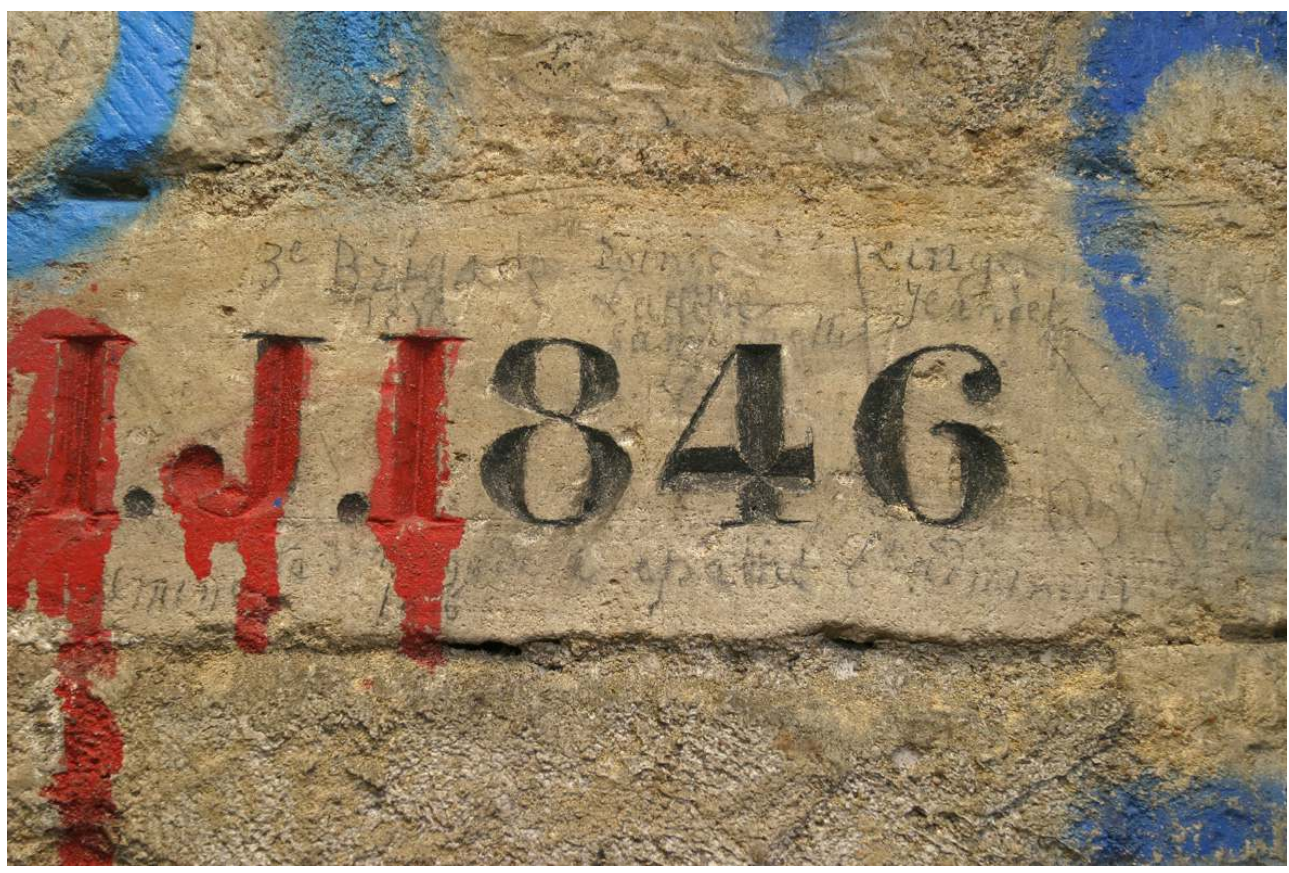

Sur ce pilier de consolidation daté de 1846 et réalisé sous l'Inspectorat de Juncker, on peut encore lire, malgré des traces de peinture récentes dues à des cataclastes, au-dessus du graphisme officiel de I'Inspection des carrières « $3^{\text {e }}$ Brigade 1876 Poincaré Laffitte Sanguinetti Linget Jeantet », donc les noms de 5 élèves et en-dessous « $3^{\text {e }}$ Brigade a épaté l'administration ».

(c) Albaret, Franck.

En revanche, certains de ces élèves Mineurs feront parler d'eux pendant la guerre francoprussienne. En effet, le 11 septembre 1870 vit la formation d'un bataillon de mineursauxiliaires du génie (suite à une décision ministérielle de la veille ${ }^{45}$ ) dans lequel furent incorporés tous les jeunes ingénieurs des Écoles des Mines alors présents dans la capitale, ainsi que le personnel du Service des carrières de Paris. Pendant le siège de 1870, les travaux de consolidation des carrières situées sous l'enceinte dite de Thiers furent bien évidemment interrompus, d'autant plus qu'il avait été constaté qu'il n'y avait nulle part de danger d'accidents immédiats. On s'en tint alors à faire de simples reconnaissances, qui servirent aussi à mettre en relation certains des forts du sud de Paris avec la capitale. C'est l'ingénieur Coullard Descos qui dirigea le bataillon devant mettre en communication les forts de Vanves, Montrouge et Ivry, avec Paris. Ces travaux furent exécutés, entre autres, par les élèves-ingénieurs Zeiller, Heurteau, Bertrand et Durand de Grossouvre. Des noms que l'on a retrouvé écrits de leurs propres mains par les impétrants, lorsqu'ils n'étaient encore que de simples élèves aux Mines, quelques années auparavant ${ }^{46}$. (fig. $\mathbf{n}^{\circ}$ 13) (fig. $\left.n^{\circ} 14\right)$ 


\section{Figure 13}

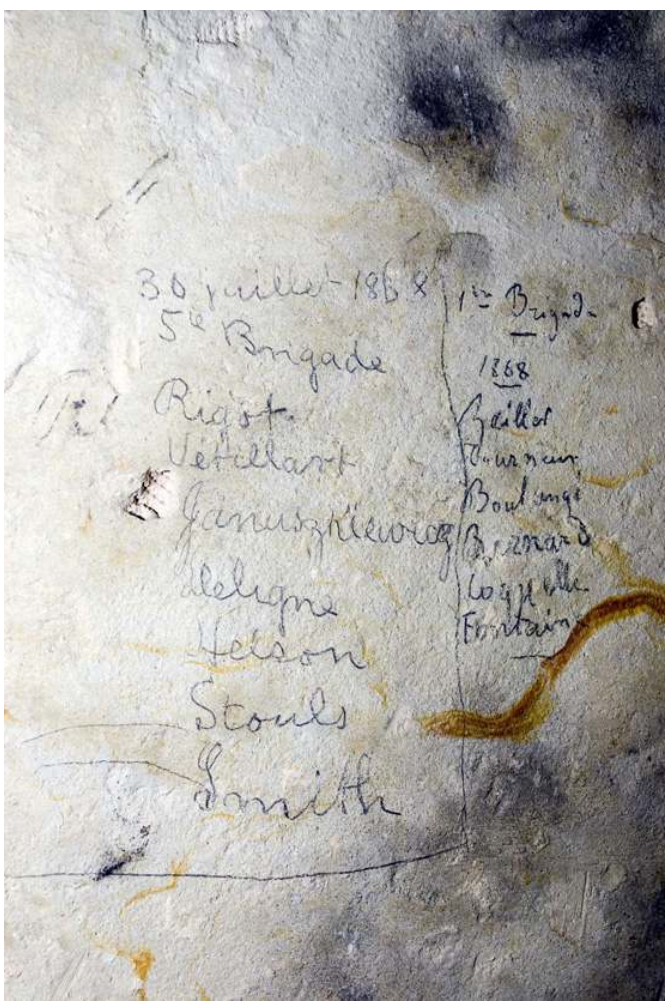

Inscription laissée par l'élève Charles René Zeiller (X65) de la promotion 1867 aux Mines 67 lorsqu'il fit son exercice topographique en 1868, en compagnie de Pereyra, Vivarez, Diano (un élève étranger admis par équivalence) et Fabre. À côté, le cartouche laissé par la $5^{\mathrm{e}}$ Brigade de la même promotion, le 30 juillet 1868.

(c) Albaret, Franck. 


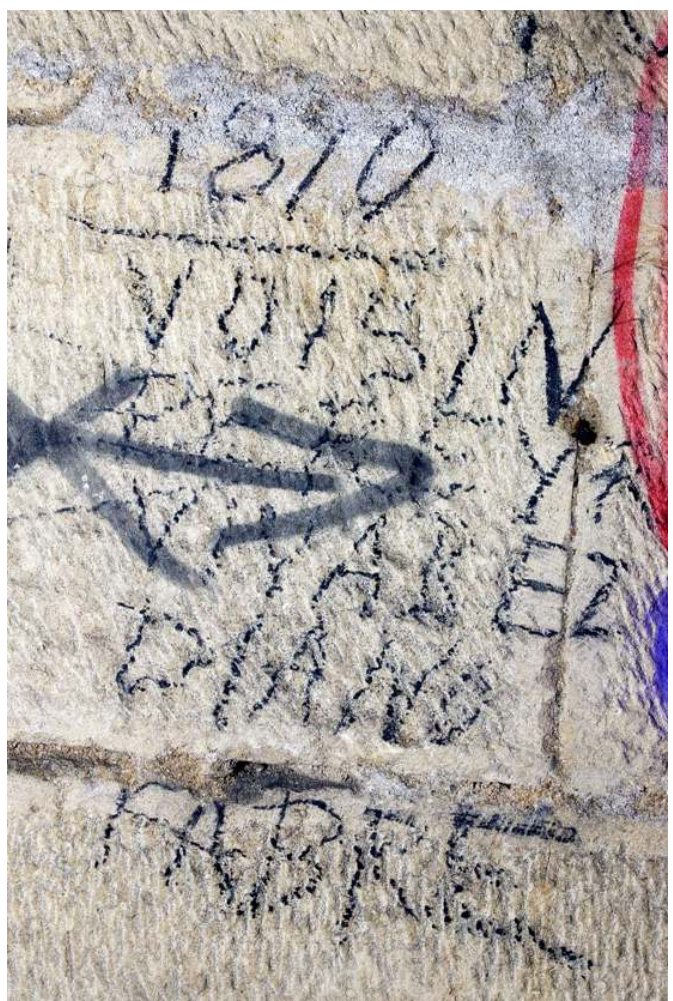

Inscription laissée par l'élève Honoré Voisin (X67) de la promotion 1869 aux Mines pendant son exercice en 1870. Dans sa brigade, la 1 ère de la promotion, se trouvaient Tourneur, Boulangé, Bernard, Coquelle et Fontaine.

(c) Albaret, Franck.

Parmi les jeunes ingénieurs issus des Mines mais aussi des Ponts et Chaussées, certains furent associés aux travaux entrepris par Descos. Il s'agit, dans le corps des Mines, des ingénieurs Jordan (Camille, inspecteur particulier à l'Inspection des carrières, élève des Mines de la promotion 1857), Worns de Romilly (Paul ; X57, Mines 59), Michel-Lévy, Douvillé (Henri ; X63, Mines 65) et Clérault (Charles ; X63, Mines 65); des élèves Zeiller (Charles René, qui deviendra un savant célèbre en paléontologie végétale ; X65, Mines 67) qui fut lieutenant des mineurs auxiliaires du Génie, Henry (Adolphe) et Heurteau (Émile), tous deux de la promotion 1867 des Mines, Amiot (Henri) de la promotion 1868; en firent également partie Voisin (Honoré ; X67), Boutan (Edmond), Bertrand (Marcel), Durand de Grossouvre (Félix ; X67) et Le Verrier (Urbain) tous les cinq de la promotion 1869 des Mines. Du corps des Ponts et Chaussées, provinrent les ingénieurs Heurtier, Lax et Choquet. Le bataillon des mineurs auxiliaires compta également dans ses rangs M. Cazin, professeur de physique au lycée Condorcet, Bouchon et Boulangé, élèves de l'École polytechnique, Bréguet qui le deviendra par la suite, ainsi que Joseph Bertrand étudiant.

En 1870, c'est le 12 juillet que se déroule l'exercice pratique de topographie des 34 élèves de la promotion 1869. La deuxième Brigade d'élèves dite "La Travailleuse " (chacune se donnait un surnom), laissa une trace de son passage dans les carrières au cours de cet exercice, sous la forme d'un petit cartouche dans lequel on pouvait lire au début des années 1980 les noms suivants : Durand de Grossouvre / Andrieux / Bibas / Chapoteaut / De Mauroy / Demarchi / Rigaud parti pour l'armée du Rhin / 12 juillet 1870. Bien que le dénommé Rigaud soit absent pendant l'exercice topographique souterrain de sa Brigade, ses camarades avaient tenu à l'associer dans la liste des 
élèves constituant leur groupe. Malheureusement, cet écrit devenu historique ${ }^{47}$, a depuis été détruit par un tag.

C'est Félix Durand de Grossouvre, le seul Élève-Ingénieur de cette brigade, qui en était vraisemblablement le « chef », le Brigadier dans l'argot de l'école, responsable de ses camarades. Edgar Rigaud, Élève-Titulaire, périra durant la guerre de 1870-1871, ainsi que Jean-Baptiste Andrieux autre Élève-Titulaire de cette même brigade.

$\mathrm{Au}$ moins une fois, l'existence de ces exercices topographiques transparut dans la presse au vu et au su des non-initiés, non pour en parler en tant que tel, mais du fait d'un incident. Ainsi, au début des années 1920, un élève des Mines s'égara dans les carrières de Paris. Son aventure fut relatée jusque dans des journaux étrangers à l'époque, et il fit même l'objet du troisième et dernier acte de la Revue (i.e. la pièce de théâtre parodique) des élèves de cette année : «Tout dit : Mine Hurrah $»^{48}$. Dans la presse, la confusion étant manifeste entre les carrières dites catacombes, et les Catacombes, autrement-dit l'ossuaire, il fut alors fait allusion à des crânes et autres ossements qui auraient tenu compagnie durant sept heures à notre jeune étudiant de vingt-trois ans, Georges Tessier (en fait Paul Teissier selon les registres de l'école) lorsqu'il tomba en panne de lumière.

\section{Le baptême de chacune des promotions de l'École des Mines de Paris}

\section{Quand l'Ossuaire de Paris prend des allures de Catacombes romaines}

Les Mineurs développèrent en parallèle une tradition de baptême souterrain, une autre raison pour eux de descendre sous Paris, aux fins d'y célébrer leur patronne (SainteBarbe) et y faire la fête, avant que d'y retourner par pur plaisir de l'exploration et de la découverte.

Si nous ne savons pas exactement à quand remonte cette idée - déclinée depuis sous forme d'une coutume codifiée -, il existe à l'école des Mines une peinture sur toile illustrant le Baptême de la promotion de 1923 (fig. n $\left.^{\circ} 15\right)$. Ce rituel baptismal dans des catacombes, fussent-elles parisiennes, cela revêt indéniablement un caractère de cérémonial secret à l'image de ceux pratiqués dans la Rome antique. Du reste, dans le cadre de cette initiation, se déroule une véritable immersion souterraine aux deux sens du terme, puisqu'une étape consiste à plonger la tête de chaque candidat dans l'eau du baptistère de la Fontaine de la Samaritaine, aussi appelée source de Léthé ou de l'Oubli, mimétisme qui renforce encore la similitude avec un rite religieux (fig. $\left.\mathbf{n}^{\circ} \mathbf{1 6}\right)$. 


\section{Figure 15}

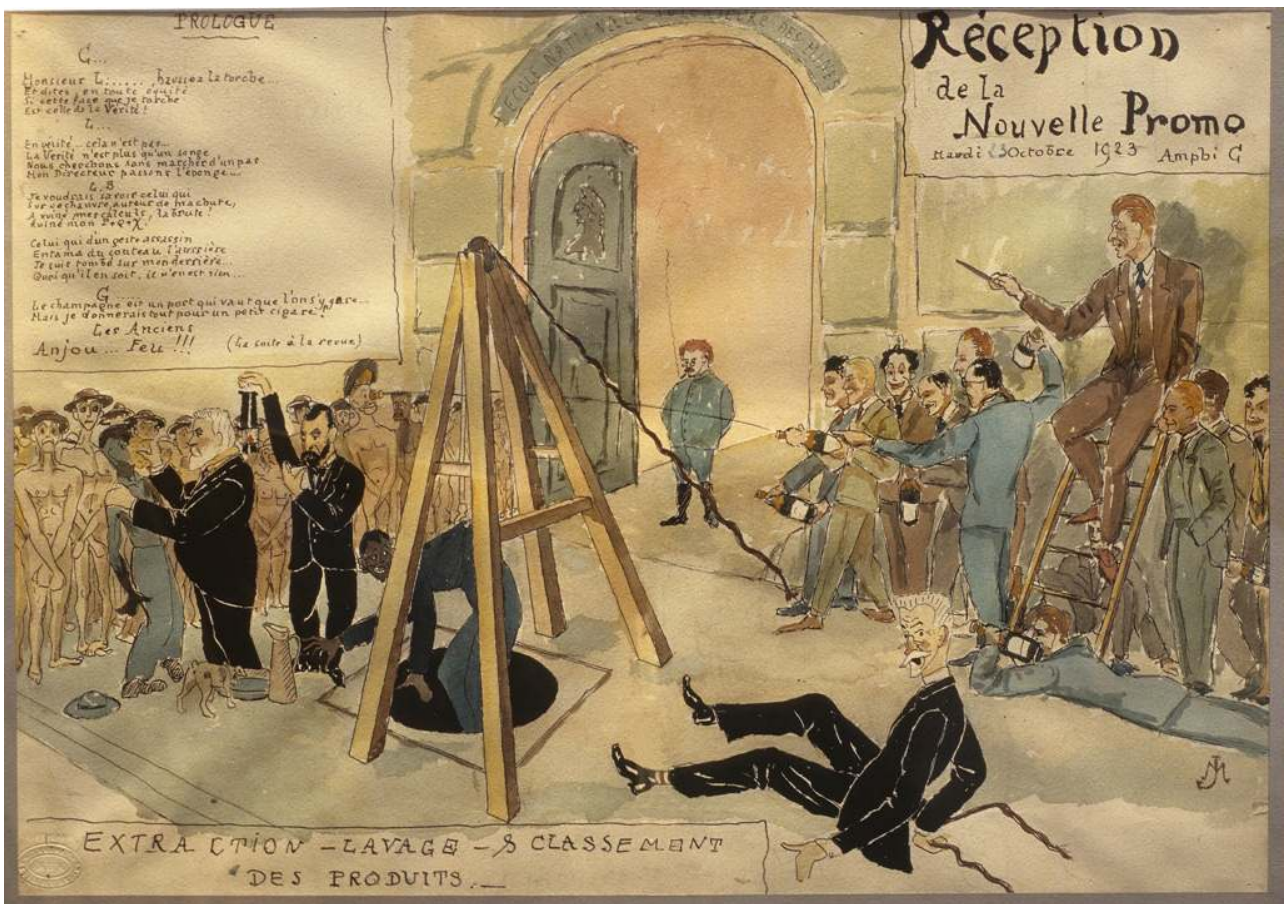

Tableau de 1923 montrant la « réception » de la nouvelle promotion. On y reconnaît le porche de l'hôtel Vendôme, adresse de l'École Nationale Supérieure des Mines, où vont se diriger les élèves pour la suite des festivités. Ils sortent des anciennes carrières souterraines de la ville par un puits de service comme il en existe de nombreux dans Paris, venant d'y subir le rite de leur baptême traditionnel.

(c) Faÿ, Olivier, 1999 (Collection MinesParisTech). 


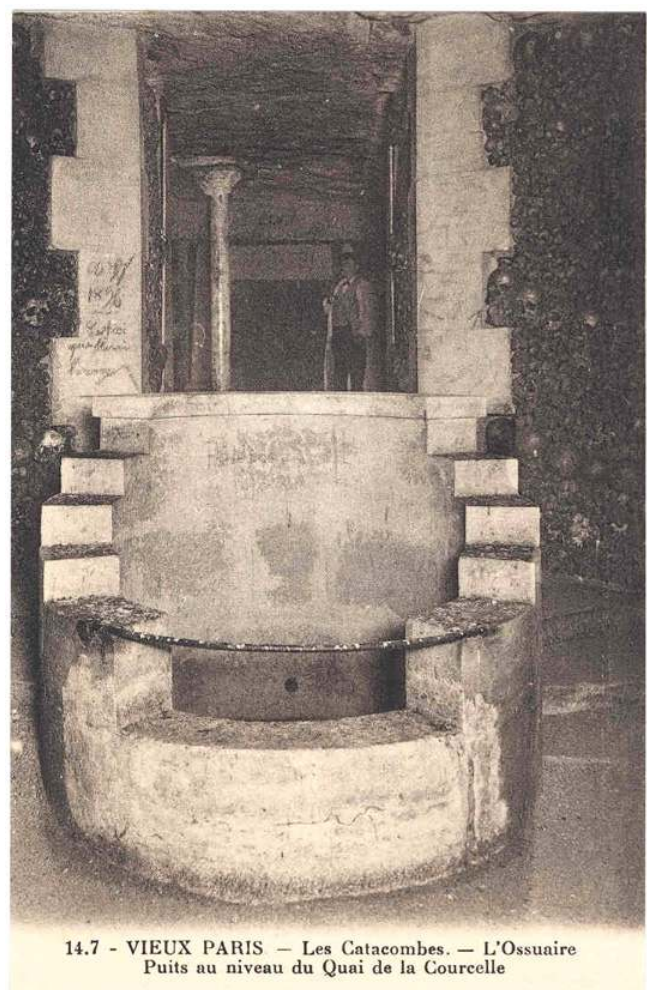

Sur cette carte postale ancienne montrant l'emplacement précis du rite baptismal, la légende est doublement erronée puisque, s'il existe des boulevard et rue de Courcelles à Paris, ces voies sont dans le $8^{e}$ et $17^{e}$ arrondissement, donc Rive Droite ; or les galeries de carrières et catacombes de Paris sont principalement Rive Gauche, à l'exception d'un réseau sous le 16e arrondissement. En revanche, s'il existe bien un quai de la Tournelle dans la capitale, au niveau de la fontaine de la Samaritaine ici photographiée se trouve un graphisme officiel faisant référence à l'altitude du lieu par rapport au pont de la Tournelle (ancien système parisien de nivellement), d'où la confusion de l'auteur de la légende.

collection particulière.

La première trace retrouvée dans les écrits estudiantins du baptême de la nouvelle promotion est datée de décembre 1944: "BAPTÊME DE LA PROMO 44. "Tiens, ce sympathique chamal ${ }^{49}$ serait-il notre marraine ?" Mlle Denise ${ }^{50}$ vient en effet d'arriver et nous voilà partis en file indienne pour la visite des catacombes: "Initiation de fond". Après une descente de $30 \mathrm{~m}$. par une bouche d'égout ${ }^{51}$, nous sommes vite, après l'aspersion baptismale au milieu des crânes et des tibias, les yeux fixés sur des visions tragiques, les oreilles à l'écoute des bruits "Tout à fait insolites"... Puis c'est un magnan ${ }^{52}$ et des chants, et malheureusement trop tôt, le retour à la surface. Nous n'insisterons pas sur la nuit qui devait nous procurer le repos nécessaire pour la cérémonie officielle du baptême du lendemain ... $»^{53}$. Le signataire de cette notule, A. Espinasse, la conclut par l'interjection classique « CHIC à la Mine-sans-Faille». (fig. n ${ }^{\circ}$ 17) (fig. $\left.{ }^{\circ}{ }^{\circ} 18\right)$ En 1946, dans une des galeries souterraines surnommée de nos jours "galerie des promotions", fut décidée la réalisation d'un tableau commémoratif, principe pérennisé depuis puisqu'il s'est renouvelé d'année en année, devenant ainsi une institution de fait qui perdure toujours en 2010. C'est Jean Rives (P45) qui eut pour la première fois cette idée, lorsqu'il était délégué général de sa promotion, sans penser à mal ni au lendemain; et il eut la surprise à la veille de sa mort d'apprendre que ce qu'il avait spontanément imaginé et conçu comme une réalisation éphémère et spontanée, se poursuivait encore et toujours. 
Cette illustration picturale de plusieurs mètres carrés est bien évidemment destinée à être vue uniquement par d'autres visiteurs clandestins, car installée sur des "cimaises » souterraines non ouvertes au public puisque nécessitant une autorisation et que celle-ci n'est jamais accordée. À l'origine, ces « panneaux » revêtaient plutôt la forme de tableaux d'honneur, car ils n'étaient constitués que d'un entourage encadrant le numéro d'ordre de la promotion ${ }^{54}$, le nom de la marraine (issue des médias ou du milieu artistique), ainsi que celui du «VP-Cata " (l'organisateur dudit baptême) accompagnés de ceux faisant partie, selon les époques, du "Club Cata» ou des "fanas-catas " ${ }^{55}$ et ayant aidé à l'organisation. Depuis, ces tableaux commémoratifs se sont vu progressivement agrémentés d'un dessin haut en couleurs, et il est maintenant possible d'y distinguer les signatures des « fresqueurs ». Si, depuis 1955, il est officiellement interdit de se promener dans les anciennes carrières souterraines sans autorisation, ce qu'obtiennent très facilement les Mineurs pour le mois préparatoire à leur baptême, il n'en demeure pas moins qu'il y a toujours des élèves dans chaque promotion de baptisés qui deviennent « accro » à la fréquentation des carrières, et y retournent alors régulièrement en dehors de toute « légalité », bravant ainsi cet interdit.

Figure 17

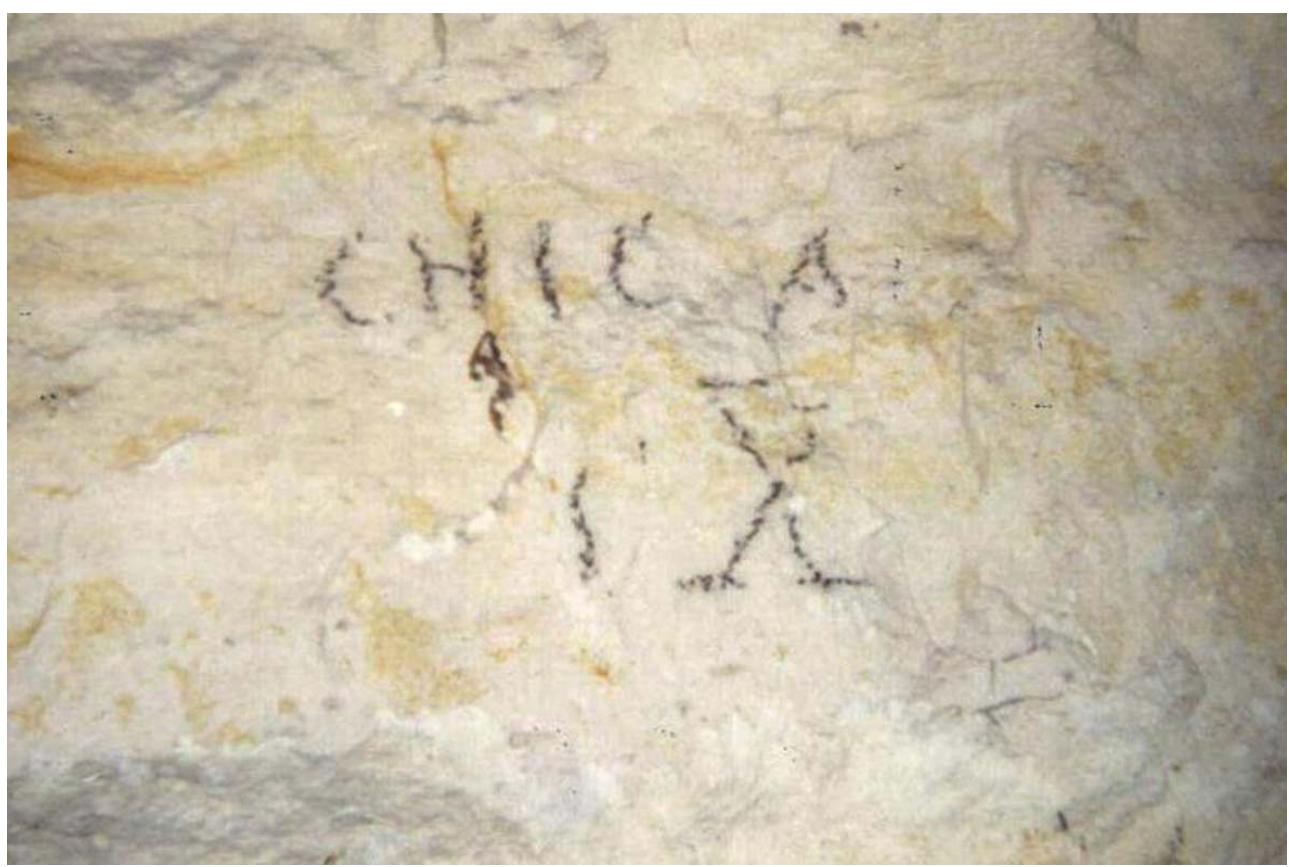

Dans les Grandes Écoles concurrentes que sont Centrale, les Mines, Polytechnique, des expressions aujourd'hui un peu tombées en désuétude se répondaient d'écho en écho. "Chic à [sa propre école] », et son contraire « Hure à [une école concurrente] », cette dernière formulation semblant avoir totalement disparu du vocabulaire estudiantin.

(c) Photo Largier, Jean-Luc. 


\section{Figure 18}

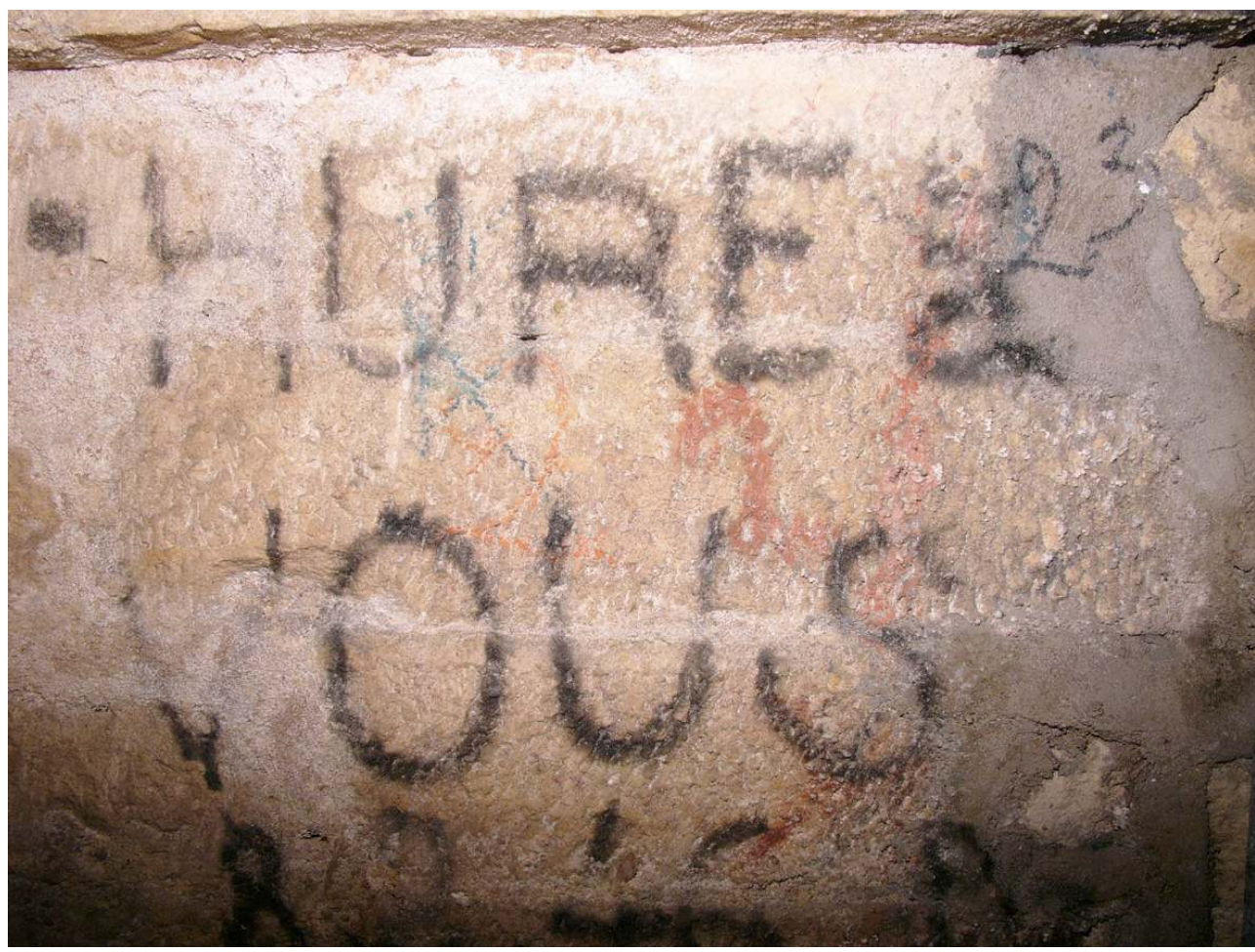

Ce « Hure à Vous » (que l'on peut interpréter par « Honte à Vous ») date de 1946. C'est infiniment plus correct à défaut d'être respectueux que « M... à celui qui le lira! ».

(c) Joli, Frédéric, 2008. 


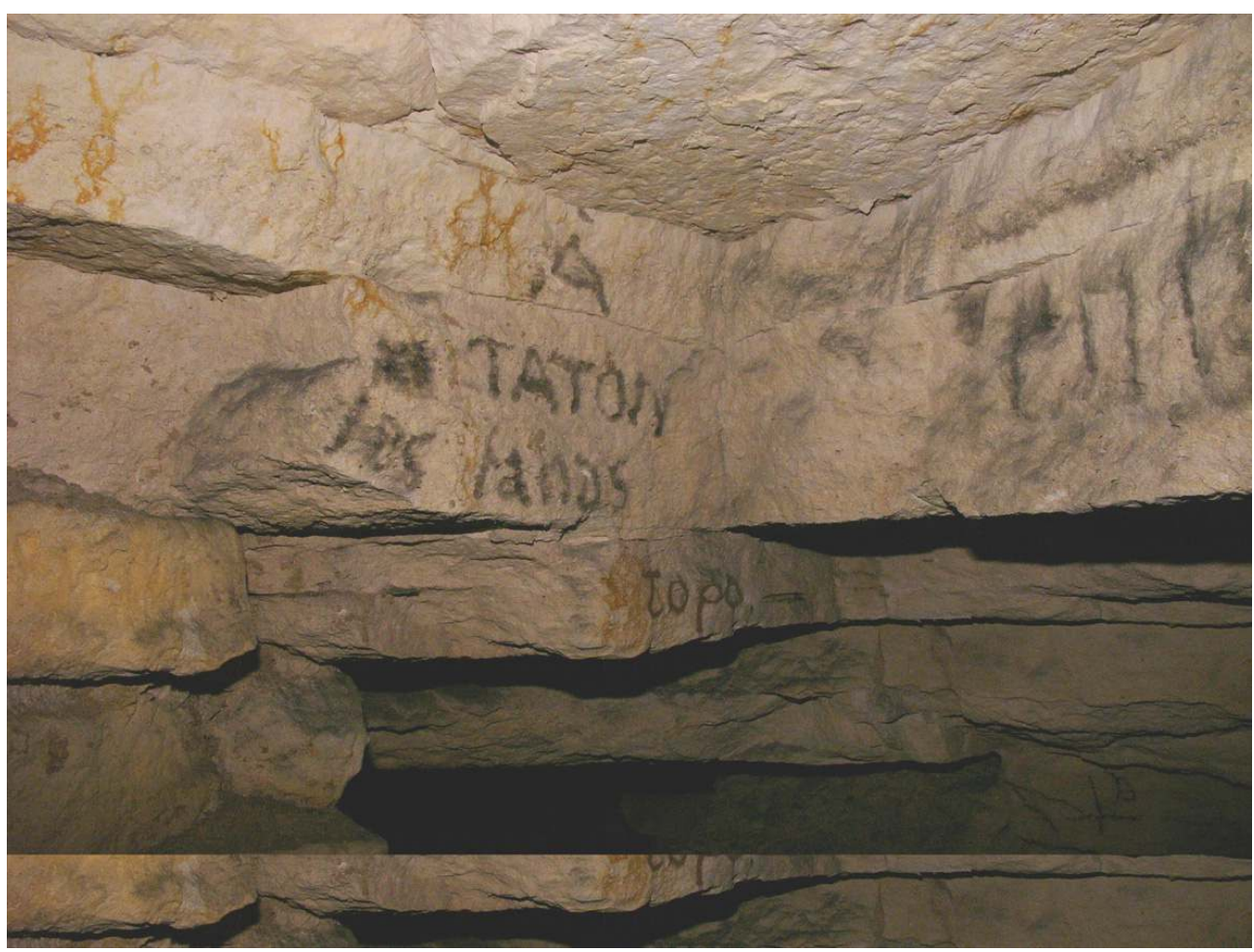

Parmi les clubs d'activités extra-scolaires qui fleurissaient au sein des Grandes Écoles, aux Mines comme à Polytechnique, le club « Cata » est un regroupement récurrent d'élèves qui découvraient au départ les carrières lors de leur travail pratique de topographie souterraine ; puis, cet enseignement ayant disparu, le baptême ou sa préparation se substituèrent à cette initiation. Ici il n'y a aucune ambiguiité puisque des élèves ont écrit qu'ils étaient « fanas de topo », tout en dédiant leur manifeste à leur professeur Robert Taton.

(C) Joli, Frédéric, 2008.

\section{De la littérature underground des souterrains}

En parallèle, dès le tournant du $\mathrm{XX}^{\mathrm{e}}$ siècle et à l'image d'autres écoles, les élèves Mineurs organisèrent une Petite Revue parodique revêtant la forme d'une pièce théâtrale, entrecoupée de chansons inspirées des meilleures comédies musicales; si ce n'est que celle-ci n'est jouée qu'une seule fois (fig. $\mathbf{n}^{\circ} \mathbf{2 0}$ ). En mars 1905, la première Revue fut jouée au théâtre du Vieux Colombier, devant un public d'élèves ; on put y entendre :

Aux Catacombes (lettre) (Air : À Saint-Lazare)

C'est de d'sous terre que je t'écris

Ma p'tit' poulette.

Si t'aim' ton p'tit' Coquelet d'mari

L'fais pas cornette!

C'est ça qui va bien m'tracasser,

Ma chère colombe

Pendant trent' jours que j'vais passer

Aux Catacombes.

Tu t'figur' pas la gueule que $\mathrm{j}$ 'fais

C'est un' misère !

$\mathrm{Au}$ fond de ce trou noir et frais 
Oh! yaye ma mère !

L'eau partout dans ce lieu d'horreur

Dégoutte et tombe ;

Sûr, je r'viendrai perclus d'douleurs

Des Catacombes.

Mais vois-tu c'qui m'écœur' surtout

C'est les odeur-re

Tu sais bien qu'mon nez recueil' tout

Par son ampleur-re ;

Elles sont bizarrement parfumées

Et ell'se bombent

D'patchouli, les gal'ries barrées

Des Catacombes

Et par d'ssus tout ces embêt'ments,

Y'a autr'chose ;

Je m'fais engueuler constamment

Ça c'est pas rose,

Par les élèves, larbins, Pelletan,

Et par tout le monde.

Bref j'm'fais engueuler tout l'temps

Aux Catacombes.

J'termine ma lettre en t'embrassant

Adieu ma belle!

Bien qu'je n'suis si séduisant

Que Déchanelle,

Tu sais bien qu'ça n'se verra pas,

Quand seuls dans l'ombre,

Ton beau corps me consolera

Des Catacombes! 
Figure 20

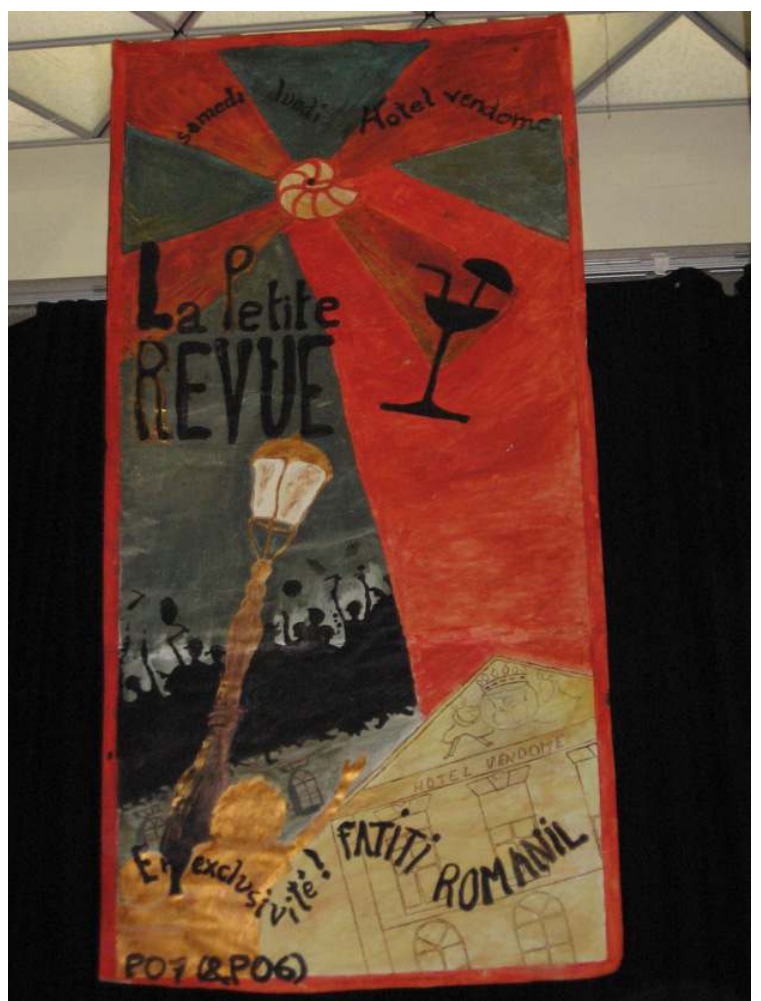

Calicot annonçant la Petite Revue en l'Hôtel Vendôme, autrement dit au sein de l'école des Mines. Parmi les traditions maintenues dans cette école, subsiste cette «PR » ou Petite Revue, pièce théâtrale parodiant les professeurs, l'enseignement et la vie à l'école. Elle est jouée et chantée une seule fois, et de plus en plus les étudiants y intègrent des scénettes scénarisées et filmées, voire reconstituées en images de synthèse. Si la marraine y assiste, elle n'y tient plus un rôle comme c'était le cas au début du vingtième siècle, lorsqu'elles étaient choisies parmi les actrices de théâtre. DR.

30 Parmi les Mineurs, c'était à qui inviterait des «Ponts " (qui partageaient parfois les mêmes enseignants comme on l'a évoqué, et de nos jours cohabitent dans le même foyer de logements estudiantins), des X (certains Polytechniciens choisissant l'École des Mines comme école d'application), ou des Z'Arts, en remerciement d'avoir musicalisé une de leurs fêtes ${ }^{56}$. Cette pratique participa aussi à la divulgation de ce qui accompagne la Petite Revue, à savoir le baptême souterrain qui commence par un parcours de randonnée dans les galeries de carrières sous la ville, et se poursuit par l'immersion dans la fontaine de la Samaritaine de l'ossuaire des Catacombes, de chacun des nouveaux élèves Mineurs.

\section{L'intégration des Mineurs par une descente initiatique}

31 L'enquête ethnologique de Barbara Glowczewski, alors missionnée par le ministère de la Culture, était limitée à la description de la fréquentation contemporaine des carrières de Paris au début des années 1980 . On peut néanmoins la considérer comme parfaitement rétroactive pour le descriptif du baptême, le rite en semblant immuable, ce que nous confirmèrent toutes les promotions interrogées, depuis la P41 jusqu'à la P74 incluse, année exceptionnelle car sans marraine! Suivant d'autre part personnellement et sans interruption ce baptême depuis 1984, je peux affirmer que cette étude est même toujours d'actualité aujourd'hui. En 1971, Jean-Pierre Vignolle écrivait déjà ${ }^{57}$ : «Répartis en petits 
groupes, les "première année", sous la conduite de leurs camarades plus anciens, passent la nuit à galoper ou à nager dans les catacombes de Paris (fig. $\mathbf{n}^{\circ} \mathbf{2 1}$ ), avec l'autorisation tacite du Service des Carrières. Le tout se termine par le baptême par immersion de chacun des membres de la promotion nouvelle dans la fontaine de l'Ossuaire ». Il précise aussi que "quelques amateurs de sport et d'émotions fortes constituent un groupe permanent (le groupe "Catas") qui, outre la préparation immédiate du Baptême (il faut chaque année démolir les murs élevés par le Service des Carrières pour interdire l'accès aux Catacombes), organise fréquemment des "descentes" clandestines dans les galeries souterraines, histoire de "maintenir la forme » et d'épater le vulgum au moyen des trophées rapportés de l'Ossuaire ».

Figure 21

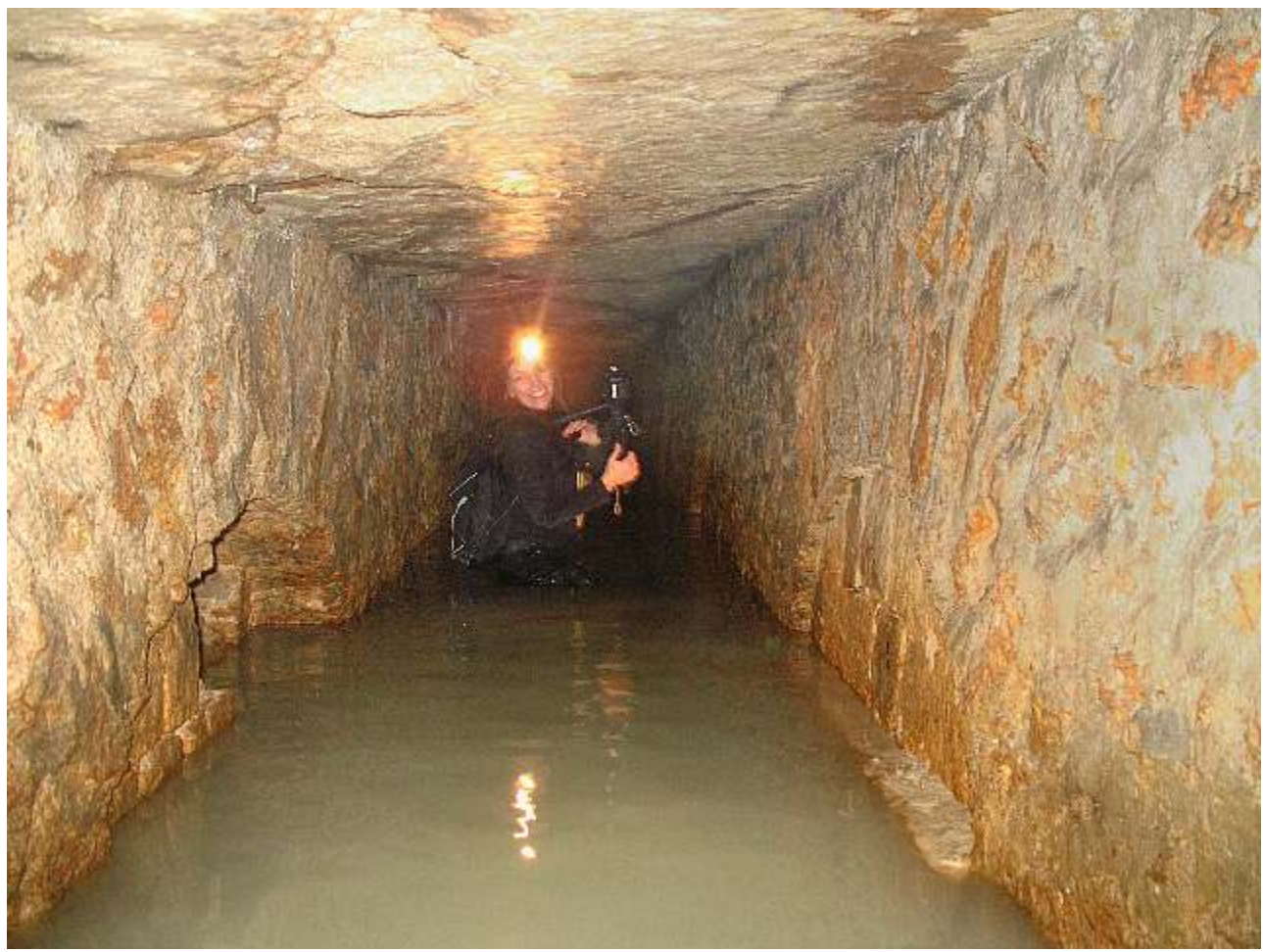

Lorsque l'on est dans les carrières / catacombes de Paris, on se trouve quasiment au niveau de la nappe phréatique. On comprend qu'au cours de « l'épreuve » du baptême, particulièrement lors de la séquence « parcours du combattant » ou « crapahut » certains se retrouvent à nager...

(c) Nel58, 2006

Cette préparation dure environ un mois. Les guides de l'année précédente (qui sont alors en troisième et dernière année) forment des élèves de seconde année à la pratique du réseau pour être les guides des cohortes de futurs baptisés. Les groupes descendent sous Paris pour un parcours qui change très peu d'une année sur l'autre. L'itinéraire du baptême alterne des «séquences "touristiques" pour la curiosité et l'édification des plus jeunes, et de séquences de "parcours du combattant" ou "crapahut" pour leur mise à l'épreuve ». Comme dans un rallye, un certain nombre de points de passage sont obligatoires. Le baptême de 1981, décrit dans le rapport pour le ministère de la Culture, détaille le parcours suivant: après s'être recueillis devant la tombe de Philibert Aspairt, fleurie pour l'occasion, les bizuts ont suivi successivement les galeries sous l'avenue de l'Observatoire, la rue d'Assas jusqu'au lycée Montaigne, le boulevard Raspail jusqu'à l'abri 
FFI, la rue Saint-Jacques avec la "galerie des promos ", puis la rue de la Tombe-Issoire «avec son trou creusé par les élèves chaque année et rebouché chaque année par l'administration (fig. $\mathbf{n}^{\circ} \mathbf{2 2}$ ), tout ce voyage tantôt droit, tantôt courbé, tantôt pataugeant dans la boue, tantôt progressant dans plus d'un mètre d'eau à $12^{\circ} 5.11$ reste à parcourir un boyau où il faut ramper en passant à $3 \mathrm{mn}$ d'intervalle l'un après l'autre. Au bout, c'est l'Ossuaire des Catacombes, celui que connaissent les visiteurs non clandestins du réseau. On y arrive la tête la première au bord d'un "gouffre" dans lequel on atterrit tant bien que mal. La sortie a lieu à Denfert, en ordre dispersé. Certains poussent encore jusqu'au parc Montsouris, mais la plupart ont hâte de retourner à la maison des Mines effacer sous la douche la boue, le froid, la fatigue, et, peut-être, l'ivresse d'un soir. »

Figure 22

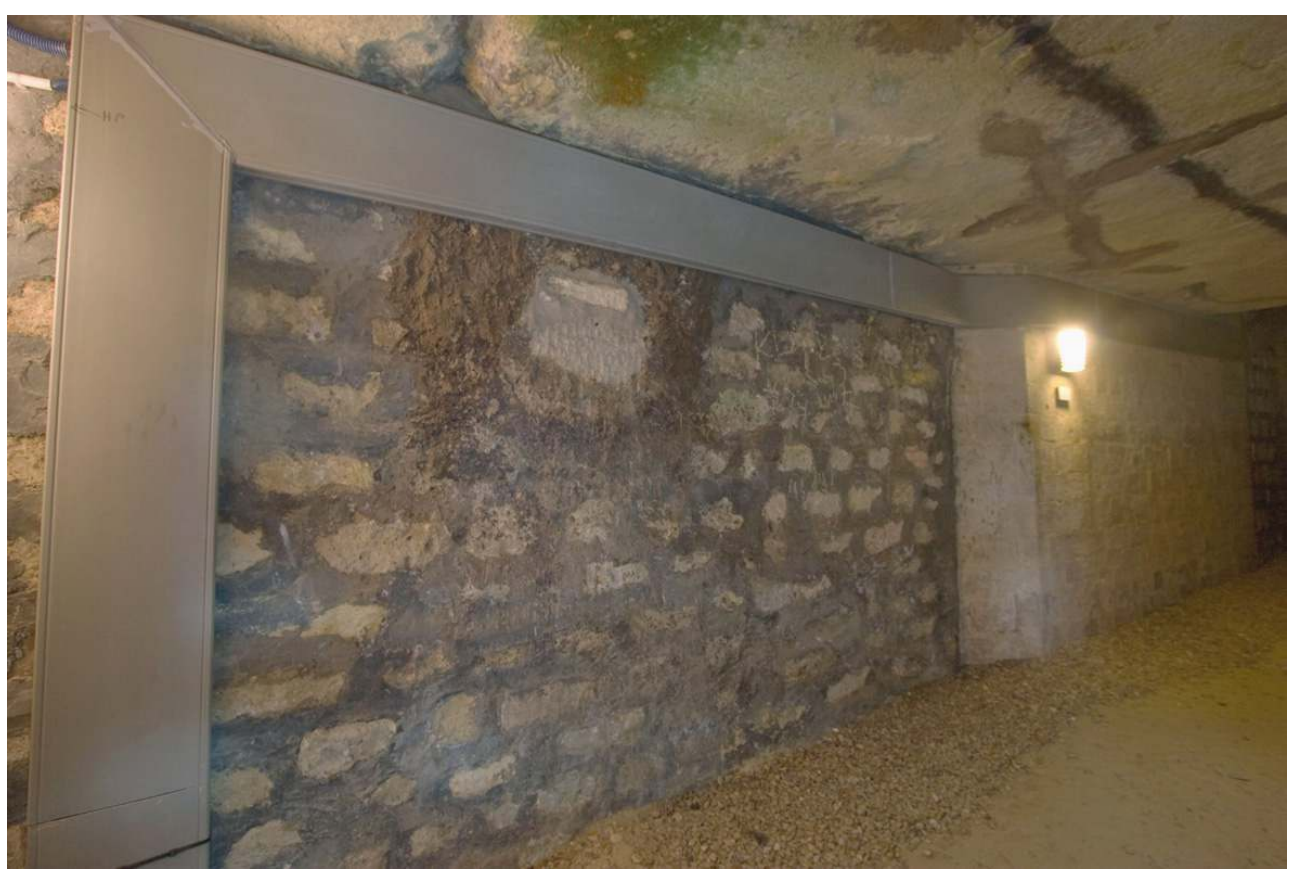

Tout ce qu'il reste « d'un trou cher à mon souvenir » pour rendre hommage au Docteur Suttel qui parle lui d'une grille chère à ses souvenirs, celle de l'hôpital Sainte-Anne, la première qu'il franchit pour partir à la découverte des «Féeriques espaces souterrains » que sont les galeries de servitude de I'Inspection des Carrières (SUTTEL, René. Catacombes et carrières de Paris ; promenade sous la capitale. Édition Sehdacs, 1986, p. 20). Cette rustine, plusieurs fois renouvelée, condamne définitivement (tout en pointant dessus) ce trou autrefois « creusé par les élèves chaque année et rebouché chaque année par l'administration » et qui permettait de faire la jonction entre les galeries de carrières hors Catacombes et l'ossuaire.

(c) Albaret, Franck, 2006.

Brigitte Larguèze en 1990 nous confirme aussi la pérennité de la chose en nous apportant quelques précisions sur la jonction entre les carrières et l'ossuaire ${ }^{58}$ : «Percée quelques heures auparavant par un groupe d'anciens à coups de pioches et de barres à mine, le franchissement de cette entrée ne se fait pas sans mal. Située au bout d'un boyau à un mètre cinquante de hauteur, l'ouverture est tellement étroite que, pour la franchir, il faut d'abord passer une épaule puis l'autre tout en se hissant. Une fois la tête et les épaules de passées, des mains vigoureuses vous agrippent et vous tirent dans un accouchement difficile. Gare à l'embonpoint qui laisse les personnes trop fortes coincées dans le passage et nécessite du renfort pour l'équipe accoucheuse constituée d'anciens. Une fois franchi ce passage difficile, le nouveau découvre le spectacle macabre des catacombes aux parois 
constituées de crânes et d'ossements. Un chemin délimité par des bougies fichées dans le sol s'offre à lui et le promène dans les allées de l'ossuaire. Le silence est sépulcral. Après un trajet relativement court mais se voulant labyrinthique, il arrive dans une petite crypte dont l'entrée est gardée par deux individus cagoulés de noir... ». Mais quoi de plus normal en fait, un baptême après un accouchement : le rythme de la vie est respecté.

\section{Le baptême à proprement parler, ou plutôt le simulacre de baptême}

En 1975, au moment de la réactivation de certains éléments du baptême (dont la Marraine de promotion absente la couple d'années précédentes) fut imaginé le recours à des individus cagoulés tels des pénitents ou des membres du Ku Klux Klan (fig. $\mathbf{n}^{\circ} 23$ ) (fig. $\mathbf{n}^{\circ}$ 24) pour impressionner un peu plus les ex-bizutés (dans les carrières) futurs baptisés (dans l'ossuaire), les deux cérémonies se succédant chronologiquement et dans la même demi-journée, qui était autrefois la nuit.

Figure 23

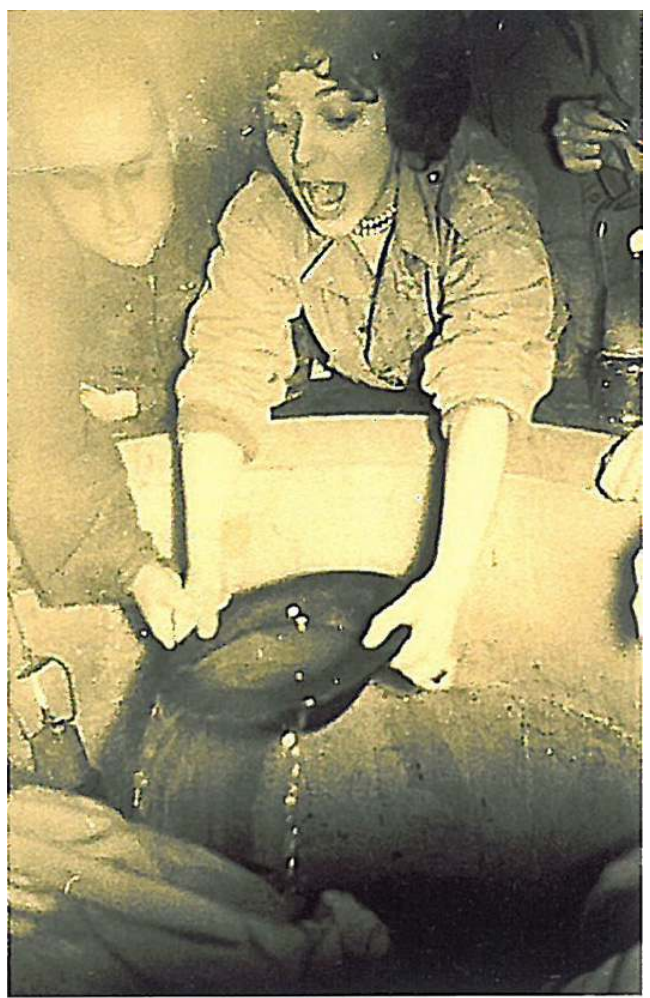

Certainement une des rares photographies prises sous terre lors des premiers baptêmes, car très peu d'élèves descendaient avec un appareil photo, même parmi les organisateurs ; ici celui de 1958. La marraine puise de l'eau dans la fontaine de la Samaritaine avec une barrette de mineur en cuir bouilli (l'ancêtre du casque), pour en arroser la tête des impétrants, apprentis Mineurs.

(c) Blazy, Maurice, 1958. 
Figure 24

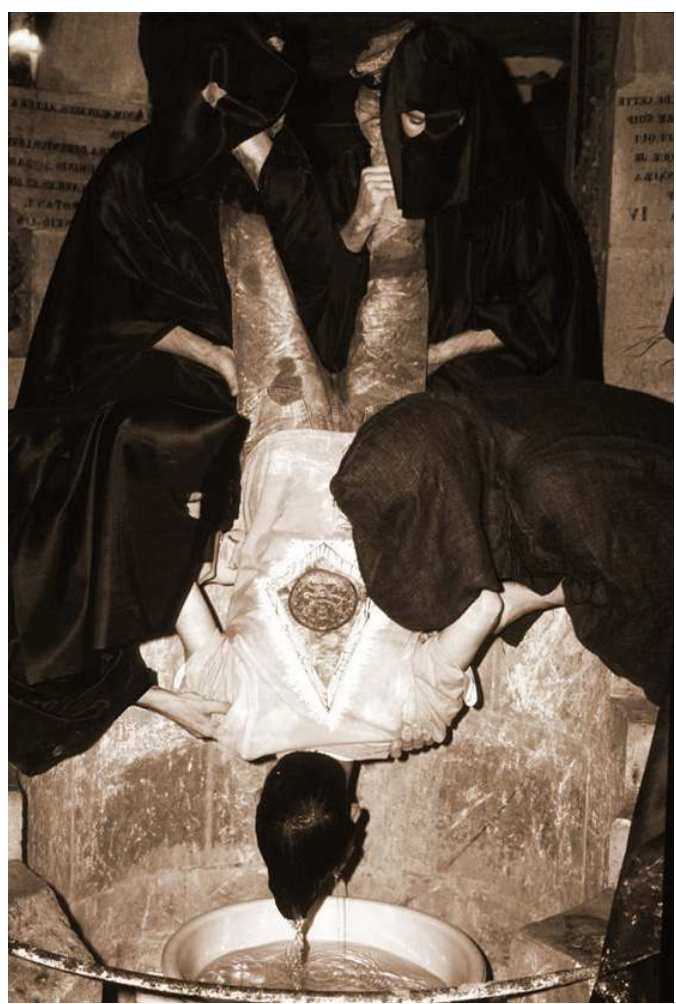

À partir du milieu des années 1970, les officiants revêtirent des costumes du style Ku Klux Klan, ou du moins pour rester dans le domaine du religieux qui sied mieux à une cérémonie baptismale, se travestirent comme ces pénitents cagoulés que l'on rencontre dans différentes confréries.

(c) Faÿ, Oliver, 1999.

Le déroulement de ce baptême a toujours été ambigu. Les élèves bravent en effet un interdit, mais munis d'une autorisation pour le faire. Autrefois, ils allaient donc jusqu'à casser un mur de séparation entre l'ossuaire et les carrières, effraction que s'efforçait de ne pas voir l'Inspection; celle-ci, bonne mère, rebouchait le trou quelques jours après, tout en continuant de fermer les yeux et en sachant pertinemment que le même endroit serait à nouveau percé l'année suivante. En outre, par cette circulation autorisée, les Mineurs jouissent éventuellement d'un privilège, mais surtout d'un lieu qui n'est pas le leur puisque de nombreuses personnes y circulent aussi, tout autant clandestinement que les élèves devenus accros à l'endroit et qui y reviennent hors baptême. Une autorisation officielle ayant donc été demandée à l'Inspection des Carrières, et la clef d'une porte confiée avec moult recommandations, les cadenas sont néanmoins changés pour l'occasion. Mais la patience peut être sans limite pour assouvir un penchant passionnel, à tel point qu'en 1995 la fameuse clef sésame fut tripliquée par un élève aujourd'hui " consultant dans un grand cabinet parisien » ... et put être utilisée tout à loisirs chaque année pendant 10 ans, lors des préparatifs du baptême!

Selon Barbara Glowczewski, le choix de marraines appartenant au monde du spectacle et donc du «simulacre » serait mûrement réfléchi : à la fois à l'image de cette parodie de baptême, mais aussi comme contre-poids à l'éducation élitiste reçue en surface et donnée par des détenteurs du savoir dûment patentés. Cette cérémonie nocturne et souterraine (donc doublement dans le noir) ayant pour vocation de railler l'enseignement, ce serait un geste de dérision par rapport à l'institution. En fait, l'explication est beaucoup plus 
terre à terre : les premières marraines étaient de jeunes actrices facilement contactables et « débauchables ». Certaines sont d'ailleurs retombées dans l'oubli aussi vite qu'elles en étaient sorties ; qui se souvient sincèrement qui était Karina Varone (marraine de 1979), simple exemple parmi d'autres? Et aucune promotion ne voulant interrompre la tradition pour ne pas apparaître comme celle qui aura cassé la chaîne, ce principe de marraine issue des médias fut maintenu d'année en année... avec néanmoins un accroc lacunaire en 1973 et 1974. En outre, les élèves des Grandes Écoles, dont des Mines, étant plutôt issus de la classe supérieure, il y a souvent quelqu'un qui connaît directement une actrice débutante, une chanteuse en devenir, à qui il peut être proposé la participation au baptême, à défaut de mieux ${ }^{59}$.

En revanche, la marraine de 2006 fut Anne Lauvergeon alors PDG d'Areva, mais facilement contactée parce que issue des Mines elle-même et ancienne adjointe à l'Inspecteur général des Carrières ${ }^{60}$. La promotion suivante se sentit obligée de suivre ces traces, s'éloignant de l'esprit originel car s'écartant de la tradition médiatique: la marraine pour 2007 fut Patricia Barbizet, haut responsable au sein du groupe d'entreprises commerciales «PPR ». Cette tentative d'écart par rapport à la "norme » ne semble pas se poursuivre puisqu'en 2008 ce fut Guillaume Gallienne, et en 2009 Peggy Bouchet ${ }^{61}$. Avec le choix des marraines autrefois fortement médiatisées, se faisait jour une dualité à laquelle la nouvelle génération permettra peut-être de mettre fin: par ce truchement artistique, le secret du baptême que voulaient conserver uniquement entre eux les élèves, pouvait être éventé. Ils risquaient en effet que quelqu'une participant à ce cérémonial le dise « assez haut pour que les médias, depuis les fondations souterraines de la cité, l'entendent : qu'une marraine, issue du monde du spectacle et de l'information descende, baptise et témoigne $»^{62}$. Après la cérémonie, chacun repart avec son certificat de baptême, en quelque sorte un premier diplôme pour ces nouveaux élèves de l'École des Mines, celui du baptisé (fig. $\mathbf{n}^{\circ} \mathbf{2 5}$ ). 


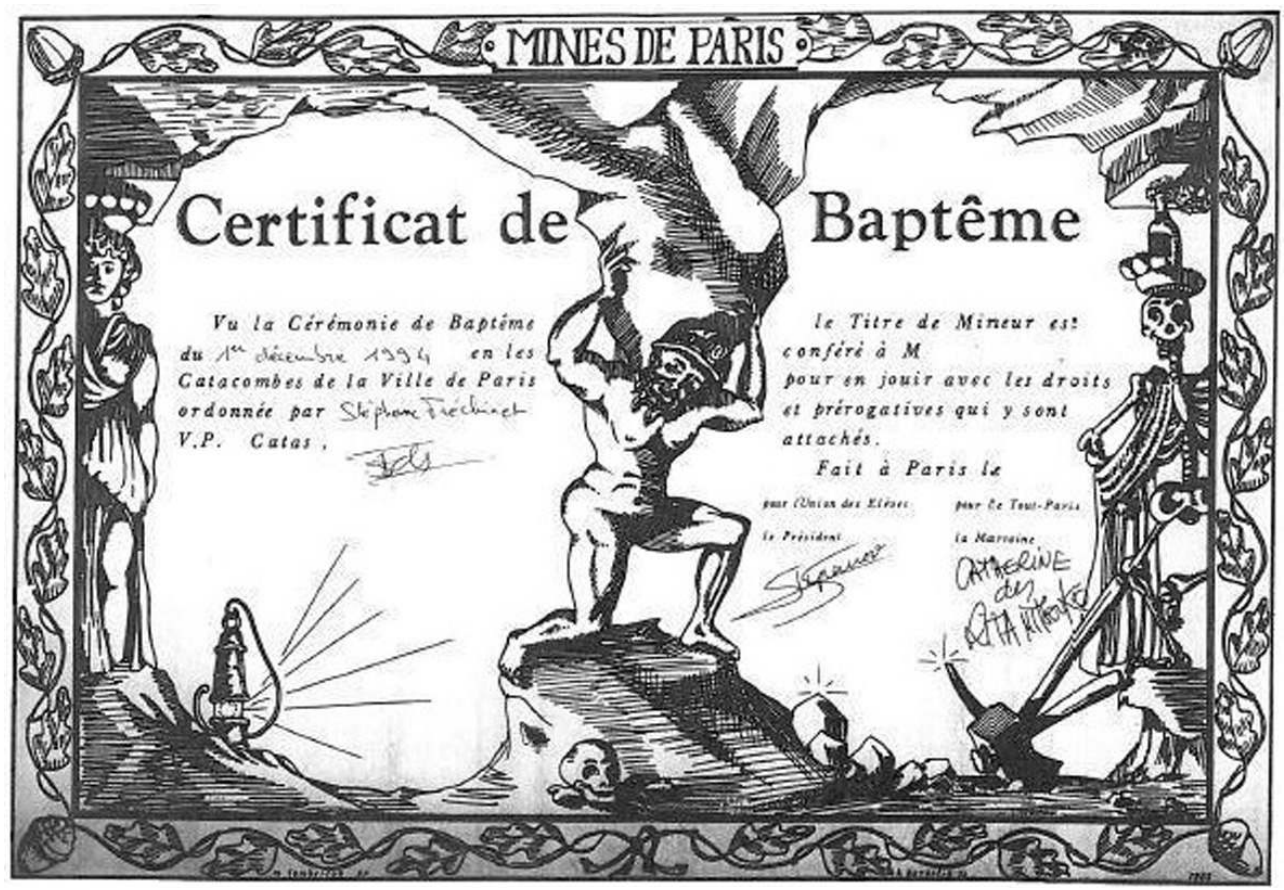

La marraine ayant signé ce certificat de baptême est Catherine Ringer, la chanteuse du groupe Les Rita Mitsouko. Donné le jour même de la cérémonie à chacun des nouveaux promus dans la communauté des élèves Mineurs, ce « diplôme » n'est pas sans rappeler celui remis dans les années 1960 par Daniel Munier aux « Chevaliers de la hague et compagnons du pilier à bras » qu'il initiait alors. II présenta ainsi clandestinement les carrières de Paris à près de 1000 personnes depuis 1957, dont vingt seraient devenues des visiteurs réguliers (des « adeptes autonomes »), tandis que son plan fut longtemps pris à tort comme étant une production d'un élève de l'École des Mines.

Collection particulière.

Se succédèrent ainsi dans le rôle de Marraine principalement des actrices, rarement des chanteuses. En voici quelques-unes, présentées dans l'ordre chronologique de leur entrée en scène : Jacqueline Duc, Danièle Delorme, Nicole Courcelle (qui fut remplacée au pied levé par une "entraîneuse »), Annie Girardot, Marie Laforêt, Juliette Gréco, Claude Jade, Bernadette Laffont, Mylène Demongeot, Marthe Mercadier, Sophie Desmarets, Charlotte Valendray, Nathalie Baye, Nicole Garcia, Marie-Christine Barrault, etc. Parmi les nonactrices, il y a donc quelques chanteuses; citons en plus de celles qui sont aussi actrices, Nancy Holloway, Marie-Josée Neuville, Catherine Ringer. On trouve aussi deux speakerines (Noëlle Noblecourt et Michèle Maillet), une clown (Annie Fratellini), une championne de natation (Roxana Maracineanu), une Miss France (Mareva Galenter), ... et même une politique (Ségolène Royale). En 2006 et 2007, c'est donc auprès des industrielles que furent recrutées ces marraines. Tandis que l'organisation du baptême a toujours été un rôle dévolu aux Mineurs de sexe masculin; jusqu'à aujourd'hui seulement deux « Minettes » (terme consacré) officièrent à ce poste, c'était en 2002 et 2008 (la parité n'est toujours pas à l'ordre du jour pour cette activité ersatz de la spéléologie, qui est un sport se féminisant néanmoins de plus en plus). 


\section{La perpétuation d'une tradition picturale et sa prolongation}

\section{Artistes en carrières et Mineurs artistes... et non pas Artistes mineurs}

Il n'est pas étonnant que sur les panneaux promotionnels des baptêmes, on puisse à chaque fois trouver représenté l'emblème des mineurs : la lampe entrecroisée du pic et de la massette. Cependant, ce n'est qu'en 1988 qu'apparut pour la première fois ce qu'on peut légitimement appeler une peinture murale (à défaut de fresque au sens étymologique), car ce ne fut plus simplement un entourage, éventuellement orné d'un objet supplémentaire ${ }^{63}$, mais un ensemble cohérent peint : cette année charnière, avait été dessiné un squelette de mineur vu aux rayons $\mathrm{X}$, portant une lampe dans le faisceau de laquelle fut inséré le nom de la marraine (Charlotte Valendray) jusque sur le plafond. Le développement de ces représentations iconiques hautes en couleurs peut avoir été influencé par l'apparition des premières peintures cataphiles réalisées par les membres du groupe informel The Rats, au tout début des années 1980.

Pour le baptême de 1998, on atteignit un paroxysme dans la représentation picturale : l'intégralité de la peinture (réalisée en 1999) est non seulement une mise en abyme de celles des trois années précédentes (95, 96 et 97), mais de plus elle représente un paysage, dans lequel la galerie de servitude au niveau des carrières de calcaire a été astucieusement convertie en une galerie de mine avec sa voie Decauville, à l'entrée de laquelle se trouve un mineur casqué, son pic sur l'épaule droite, une lampe à la main gauche (fig. $\mathbf{n}^{\circ} \mathbf{2 6}$ ). 
Figure 26

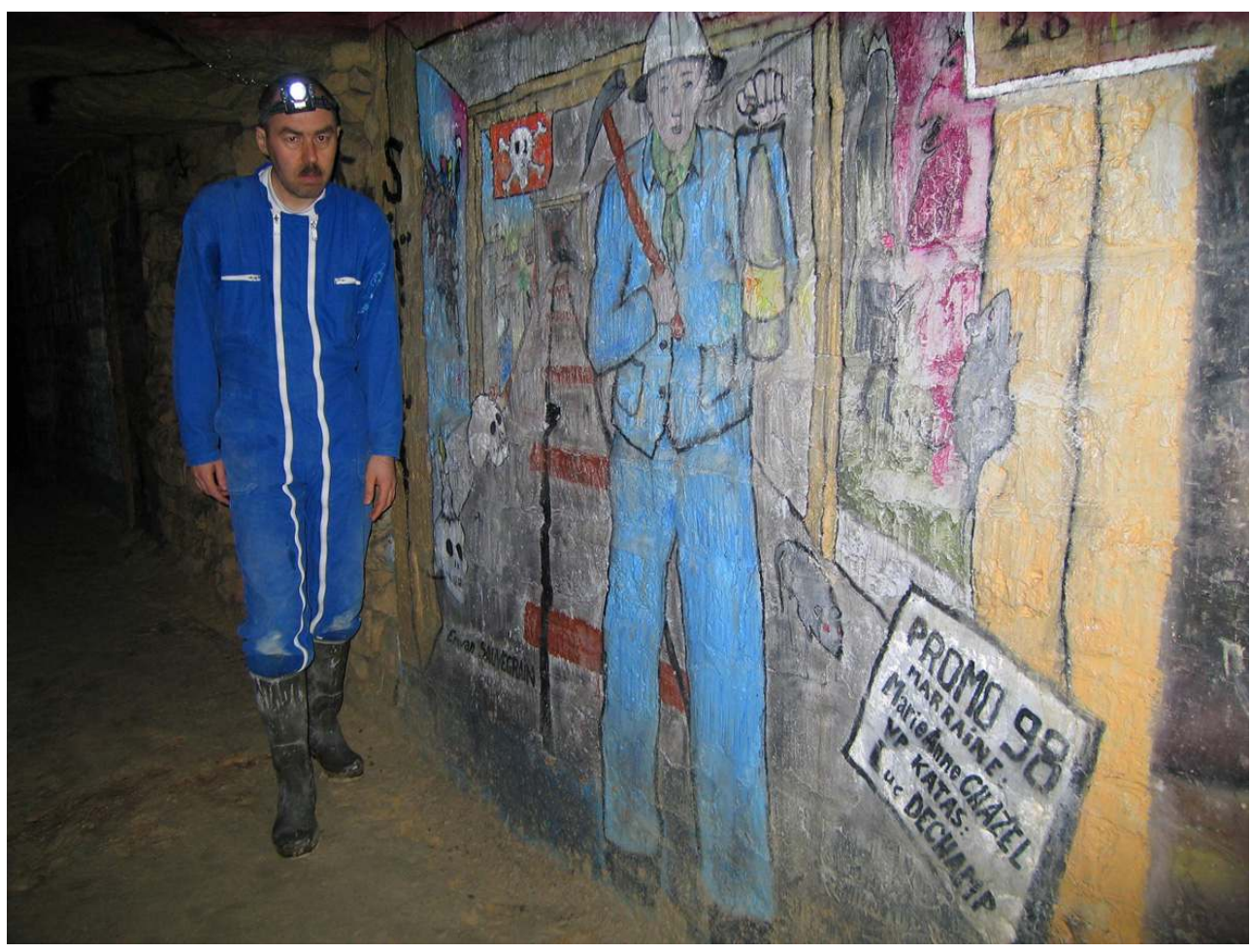

Sommes-nous dans une mine ou dans une carrière ? Quoi qu'il en soit, dans une carrière offerte à la liberté (d'expression) des Mineurs. La structure des carrières de Paris (un labyrinthe souterrain totalement dépourvu de lumière naturelle) permet en tout cas aux futurs Mineurs diplômés de ne jamais oublier l'origine du nom de leur école, même devenue « Mines ParisTech ». Ici, l'imaginaire minier est en parfaite adéquation avec la réalité des Mineurs le temps de leur baptême.

(c) Joubel, Isabelle, 2010

\section{L'existence de peintures murales sous Paris, avant celles des Mineurs}

Et si donc tout avait commencé là : «Juin 83. Un jour de fête punk. Dans les catacombes, en dessous de Denfert, ceux qui vont devenir les VLP peignent. Chacun de son côté et à la lueur des bougies. Alors, ils décident de faire une fresque commune sur les murs de l'ancien Q.G. des FTP, les résistants de 39-45, et la signent "Vive La Peinture". Un mot d'ordre minimum pour un futur qu'ils veulent maximum. L'aventure commence. VLP sera désormais leur pseudonyme. Ainsi, ils abandonnent la sacro-sainte "personnalité du peintre". Puis ils remontent à la surface, où les plus belles cimaises les attendent: les palissades des chantiers. Leur nouveau support sera peint à l'acrylique et à la bombe, puis à la laque industrielle, plus solide face aux intempéries ${ }^{64} »$, mais ceci est une autre histoire, plus « superficielle ».

Ainsi au début des années 1980 vont émerger sous terre des œuvres ${ }^{65}$, soit originales d'artistes qui depuis se sont fait un nom en surface en poursuivant leur parcours artistique à la lumière du jour (les VLP, mais aussi Jérôme Mesnager, Paella, ou d'autres ${ }^{66}$ ), soit des reproductions de tableaux célèbres dont la grande majorité est due au groupe des Rats, principalement par l'entremise et la patte artistique de Dan Sous la vague au large de Kanagawa plus connu sous le nom de La grande vague (d'Hokusaï), Guernica (de Picasso), des 
reproductions de Judge Dred (cartoon américain), de la pochette du disque Ziggy Stardust de David Bowie, d'une photo de Lily Marlène dans «L'ange Bleu », etc . Ces peintures ont été principalement réalisées dans quatre endroits, proches deux à deux : «la plage » et «le cellier », « l'abri allemand» et « le bar des rats ». En 1986 se déroula même au Cellier une véritable inauguration de la peinture d'une Piscine, recouverte pour l'occasion d'une bâche, les participants ayant été conviés par la réception d'un carton d'invitation, comme il se doit.

La décennie suivante dans le Cellier, d'autres peintures seront ajoutées : une magnifique copie de La Source d'après Ingres (en 1996) ${ }^{67}$, Le Vendeur de mort-aux-rats (de Rembrandt), ainsi qu'un auto-portrait du père de Rembrandt aujourd'hui disparu, des fresques à l'inspiration anarchisante, etc. Tandis qu'à proximité, dans la "salle Marie-Rose », on trouve entre autres les Nus sur fond rouge d'après Fernand Léger, et Sang de poisson de Gustav Klimt. < http://morthicia.free.fr/maitre.htm> et < http:// ruedeslumieres.morkitu.org/apprendre/fresques/index_fresques.html>.

C'est postérieurement aux premières réalisations des Rats, que des élèves de l'École des Mines passeront d'un simple tableau commémoratif pour le baptême de la promotion, à une œuvre dotée d'une iconographie plus aboutie ; cette première peinture montrant un squelette de mineur vu aux rayons $\mathrm{X}$, et portant une lampe dont le faisceau déborde largement des limites du bord de la « case » prévue, date en effet de 1989 (pour rappeler le baptême de 1988). Malheureusement, on peut désormais considérer que les tableaux promotionnels réalisés depuis 1945 jusqu'à 1975 inclus ont sombré corps et âmes sous les badigeons de peinture des cataclastes de passage ${ }^{68}$. Seul un œil exercé peut encore apercevoir de place en place, qui un bout d'entourage, qui une date ou un morceau de nom. Et comble de catastrophe pour l'histoire de l'École des Mines, les photos en ayant immortalisé quelques-unes se comptent aussi sur les doigts de la main.

\section{À défaut de faire carrière, certains y reviennent régulièrement}

Statistiquement, il n'est pas surprenant de trouver dans chaque promotion de Grande École quelqu'un spécialement doué pour le dessin. En atteste la réalisation, tous les ans, de caricatures des professeurs qui, soit étaient rassemblées dans un opuscule diffusé au moment d'une fête, soit agrémentaient le recueil de textes de la Petite Revue de « fin d'année " (tant à Centrale, à Polytechnique, qu'aux Mines par exemple). Il n'est donc guère étonnant de découvrir parmi les représentations picturales souvent collectives à partir du début des années 1990, certaines de très bonne facture ${ }^{69}$. C'est en 1992 qu'apparaît pour la première fois sur les parois de la galerie, donc faisant partie intégrante de la peinture, le nom des fresquistes; cette année-là, les auteurs accompagnèrent leurs identifiants du nom d'Enki Bilal, puisqu'ils reproduisirent le visage de sa Femme piège. On peut avoir une idée de ces peintures de deux façons: de manière légale, par la consultation de l'ouvrage paru aux USA en 2005 Paris Underground ${ }^{70}$, ou via une visite virtuelle grâce à des liens Internet <lien vers http://catacombes.web.free.fr/ (voir la galerie des promos dans le Grand Réseau Sud), ou bien en se rendant sur place...

Mais l'une de ces œuvres «minières » n'est pas mineure : il s'agit d'une vue des toits de Paris réalisée à partir d'une photo prise de la « Meuh » ${ }^{71}$. Elle fut peinte par un élève, qui n'en resta pas à cet essai : lui qui était revenu de son stage à l'étranger en Turquie en ayant rempli un carnet de croquis (comme cela se pratiquait au XIX siècle), reprit son pinceau de pèlerin dix années plus tard et peignit sur une porte dans les carrières un 
tableau à la manière de Mucha. Puis, en 2010 ce fut son œuvre majeure qu'il réalisa sous les caméras de National Geographic. Entre temps, en 1997, il avait déjà peint un autre Mucha sur les murs de l'École des Mines, dans l'ancien foyer des élèves, peinture aujourd'hui préservée in situ ${ }^{72}$. Depuis lors, une nouvelle œuvre majeure et véritablement exceptionnelle par ses dimensions (3,50 m de haut!), issue de la synergie entre son imaginaire et son pinceau, est donc visible sous Paris, pour qui sait chercher jusque dans les endroits les plus reculés !

\section{Figure 27}

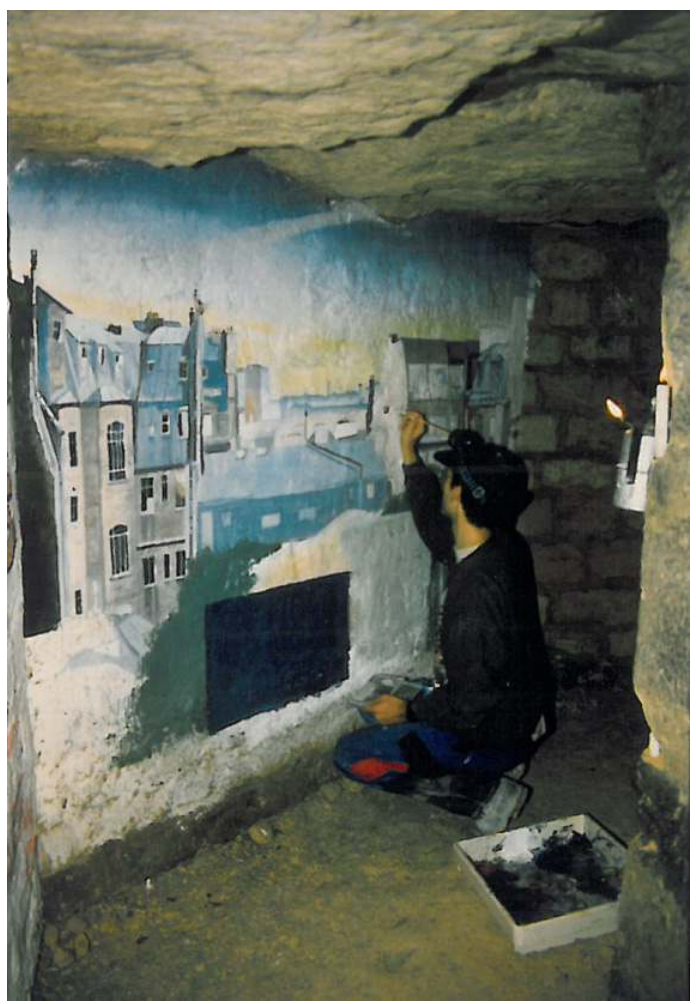

Sur cette photo on voit le travail de l'élève en train de réaliser la peinture murale qui a été dévoilée aux élèves de la promotion 1996. Elle représente une vue parisienne prise depuis le toit de la Maison des Mines et des Ponts \& Chaussées.

(c) Legrand, Jean-Yves, 1995. 


\section{Figure 28}

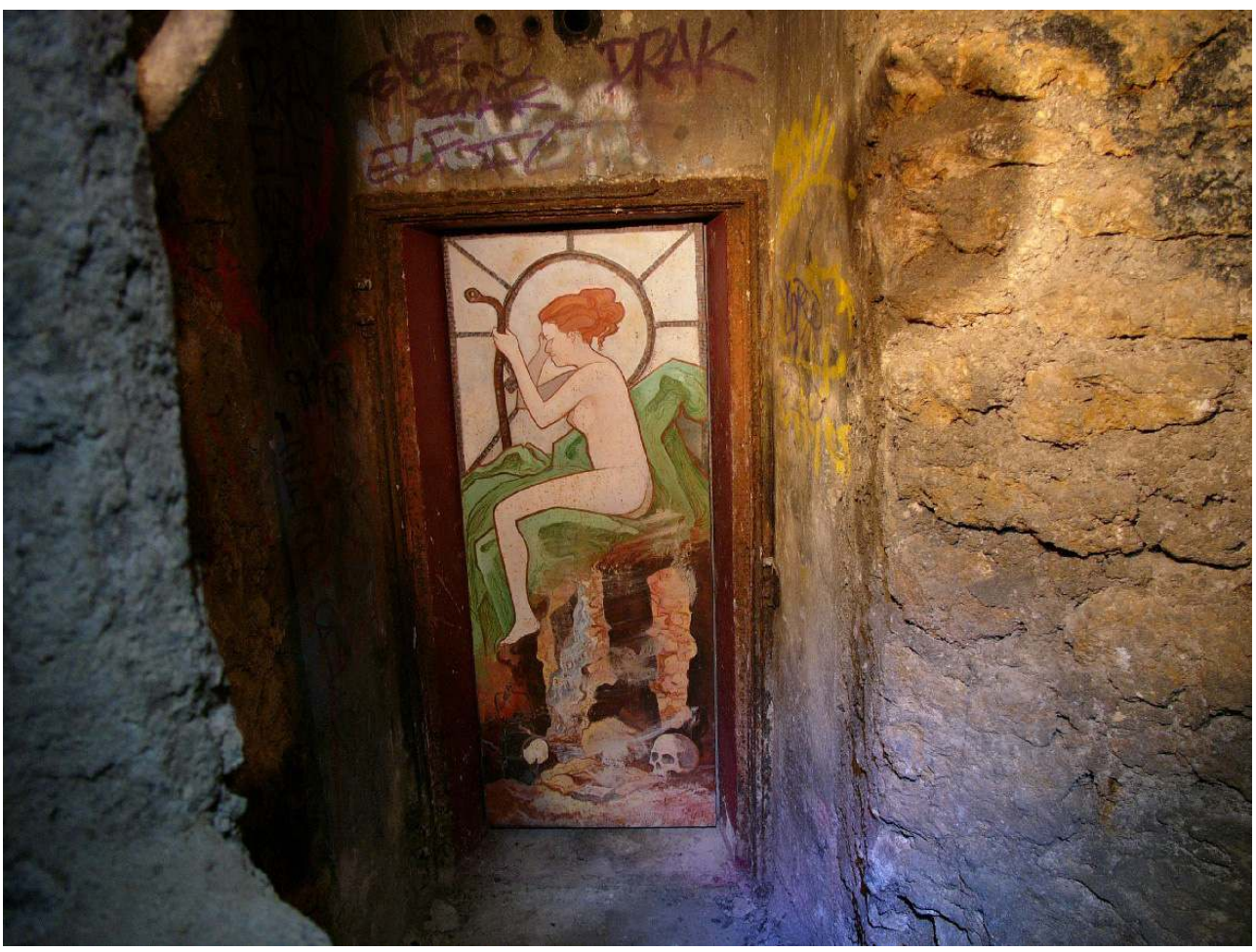

Deuxième peinture réalisée en 2005 par Lone Sloane, sur la porte séparant les sous-sols de

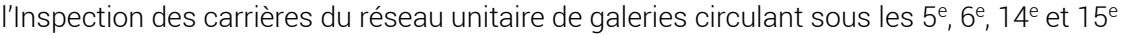
arrondissements, soit plus de 150 km de linéaires en développé.

(c) Joli, Frédéric, 2008. 


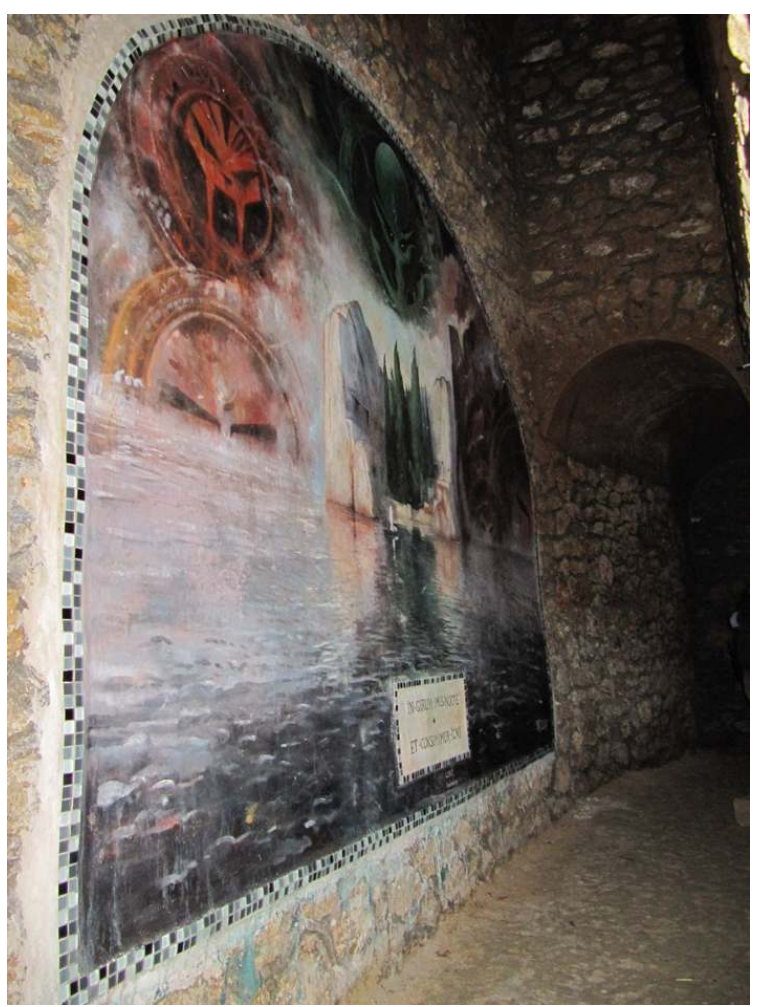

La dernière œuvre au noir de Lone Sloane, inspirée de «L'île des Morts » de Arnold Böcklin, avec des éléments en référence au dessinateur Druillet, ne fait pas moins de 3,50 m de haut. À la base se lit ce palindrome latin « In girum imus nocte / Et consumimur igni » signifiant « Nous tournons en rond dans la nuit, et sommes consumés par le feu », ce qui est de circonstance. Cette culture littéraire et artistique trouve un certain écho dans l'introduction de la Petite Revue « Les Inconnus dans la Maison », jouée le samedi 18 février 1950 : «À la lecture de ce petit recueil, on sera surpris de la diversité et de la richesse de la poétique mineure. En effet, qui avait pensé que ces réputés techniciens puissent, à leurs récréations, cultiver des genres aussi éloignés de leurs préoccupations habituelles? On les verra, en se jouant, apporter leur contribution, et non la moindre, à toutes les écoles littéraires, du classicisme le plus austère à l'érotisme le plus ambigu. »

DR, 2010

\section{(fig. $\left.n^{\circ} 27\right)\left(\right.$ fig. $\left.n^{\circ} 28\right)\left(\right.$ fig. $\left.n^{\circ} 29\right)$}

«Artistes, certains médecins le sont assurément. Au point de réaliser eux-mêmes des fresques pour les salles de garde. Cette implication directe de membres de la communauté dans la production de représentations iconiques collectives n'est pas propre au mode de l'Internat: on a souligné précédemment que le cas s'était produit à l'École Centrale, à l'École Polytechnique et bien entendu dans les écoles d'arts » a écrit Christian Hottin, chef de mission ethnologie au ministère de la Culture, dans son article sur les « Fresques des salles de garde $\aleph^{73}$. Pour une raison de non autorisation par non réponse à sa demande auprès des autorités de tutelle (transmise pourtant comme il sied par le VP Ktas, i.e. l'élève responsable du baptême, à l'actuelle Inspection des carrières), le cas des Mines n'avait pas été abordé dans son étude ; cette lacune est en partie comblée, sachant que le plus gros du travail sur ce sujet précis reste encore à faire. 


\section{En guise de conclusion}

\section{NOTES}

1. - Gilles Thomas est fonctionnaire à la Ville de Paris. Conseiller technique pour les ouvrages publiés sur le sujet des anciennes carrières souterraines de la capitale, tant en France qu'à l'étranger (Angleterre, Allemagne, États-Unis, Chine, Japon, etc.). Co-auteur de l'« Atlas du Paris souterrain ", édité en 2001 par Parigramme (prix Haussmann), il est également l'auteur de plus de soixante-dix articles sur des sujets liés aux anciennes carrières souterraines et a figuré au générique de «Ratatouille", dessin animé de Pixar. Dernière publication en date: Catacombs of Paris, Parigramme, 2011.

2. - Mes remerciements vont à Vivianne Perret pour ses encouragements, à Hélène Barthélémy pour ses relectures, et à tous les photographes (cataphiles ou non) ayant contribué par leurs photos à enrichir ce dossier (leurs noms apparaissent sous chacune de leur réalisation); ainsi que les élèves Mineurs de toutes les promotions, qui ont bien voulu répondre à mes questions depuis de très nombreuses années maintenant!

3. - Clandestine entre guillemets, car la clandestinité ne peut s'exprimer que vis-à-vis (ou en réaction) à un texte de loi, or l'arrêté interdisant « la pénétration et la circulation dans les anciennes carrières souterraines de la ville sans autorisation » ne date que du 2 novembre 1955, par mise en application de la loi sécuritaire du 3 avril de la même année prise à cause des événements d'Algérie.

4. - IMBERT, Pierre-Léonce. Les catacombes de Paris. Éditions Internationales, 1867. Il porte comme sous-titre « Guide illustré de vingt planches hors texte par Paul Perrey ». C'est la description très détaillée d'une visite clandestine qu'organisèrent les auteurs en compagnie de trois botanistes et deux touristes (terme toujours utilisé de nos jours pour désigner une personne mettant pour la première fois ses pas sous Paris). Cette promenade débuta un soir du mois de mars 1867 (à partir 
d'un puits d'un chantier de fondations), pour se terminer "le matin à cinq heures, [où] nous grelottâmes au milieu du brouillard qui s'étendait sur Paris ». Le sous-titre trompeur de l'ouvrage peut abuser les personnes qui ne l'ouvre pas ou ne connaisse pas le sujet; cela paraît être le cas de Jean-Pierre Arthur Bernard qui a écrit Les deux Paris en 2001 (éditions Champ Vallon), puisqu'il semble avoir pris au pied de la lettre ce sous-titre car il en parle comme d'un véritable guide des Catacombes publiques (p. 165)!

5. - C. Cochey, sculpteur de l'École française né à Nuits (Côte D'or), mort à Constantine en 1881.

6. - Fameux tragédien, de véritable état civil Jean-Sully Mounet (1841-1916), inhumé à Paris dans le cimetière du Montparnasse.

7. - LEFRANÇOIS, Philippe. Paris souterrain. Éditions Internationales, 1950 ; KUNSTLER, Charles. Paris souterrain. Flammarion, 1953 ; VERPRAET, Georges. Paris capitale souterraine. Plon, 1964 ; BARROIS, Maurice. Le Paris sous Paris. Hachette, 1964 ; BALI, Alain, et al. Paris sous terre. Éditions de Nesles, 1980 ; LACORDAIRE, Simon. Histoire secrète du Paris souterrain. Hachette, 1982. Et n'oublions pas que dans sa préface de l'ouvrage de 1980, Jacques Chirac semble regretter que ces galeries soient inaccessibles au commun des mortels : "Un passionnant voyage au centre du sous-sol parisien nous est offert par les auteurs de "Paris Sous-Terre" : un texte plein d'enseignements et d'impressionnantes photos révèlent l'aspect caché de Paris, ses mystères et sa beauté, son histoire et son passé. Les lecteurs découvriront une ville et une activité souterraine insoupçonnées, mais combien importante pour la vie quotidienne de ses habitants ».

8. - GLOWCZEWSKI, Barbara, et al. La Cité des Cataphiles (mission anthropologique dans les souterrains de Paris). Librairie des Méridiens, 1983 (réédité. ACP, 2008). Depuis la mi-mai 2011, un nouvel ouvrage est venu contredire cette affirmation Les Catacombes de Paris. Promenade interdite (Le côté obscur de la ville lumière), préfacé par le Commandant Jean-Claude Saratte (chez Volum éditions), conçu, textes et photos, par Gaspard DUVAL. En effet, à la suite du chapitre Histoires et légendes, s'y ouvre une partie consacrée à la «cataphilie » présentant Les cataphiles, Les cataflics, évoquant L'atmosphère (qui émane des lieux), décrivant L'équipement du cataphile, racontant des Situations délicates ou l'Organisation d'une fête, parlant des Accès clandestins et des Us et Coutumes des habitués.

9. - LEROUX, Gaston. La double vie de Théophraste Longuet. Paru en 1904 pour l'édition bibliophilique, mais dont on peut facilement trouver des rééditions. Le quotidien Le Matin prépublia cette histoire fantastique sous forme d'un feuilleton titré « Le chercheur de trésors » du 5 octobre au 22 novembre 1903 (en tout 49 épisodes).

10. - Au début de ces années 80's, tous les journaux et magazines (papier ou audio-visuels) voulurent avoir chacun leur reportage ou enquête exclusives (qui ne l'étaient donc pas) sur la fréquentation des carrières souterraines de la capitale. Certains titres se copiaient d'ailleurs joyeusement les uns les autres. Ainsi l'on a par exemple de RIVAUD, F. Mélodies en sous-sol : loin des embouteillages de surface, il fait bon vivre des aventures (interdites) dans le sous-sol de Paris. L'Express, 1981, du 27 novembre au 3 décembre; avec à l'appui une photo du bizutage estudiantin des Mineurs sous Paris.

11. - Ne pouvant prétendre aucunement à l'exhaustivité, nous signalerons que pour la période allant de 1981 à 2010, c'est une vingtaine de tels mémoires qui ont été trouvés. Ce qui pourrait faire croire qu'il y a là un sujet facile à traiter. Si en 2003, le mémoire " Promenade sous la ville » (par Baptiste Roux et Élodie Champey - École nationale supérieure d'architecture de Versailles) a été présenté sous la forme d'un court-métrage vidéo, ce n'était pas vraiment une première. Depuis les années 2000, il ne se passe pas une année sans que des élèves d'écoles journalistiques ou cinématographiques ne veuillent présenter un reportage ou un documentaire sur les carrières de Paris comme sujet comptant pour l'obtention de leur diplôme ; miniaturisation des caméras et l'apparition du numérique aidant (qui supporte plus facilement les tournages avec peu d'éclairage), cela n'est pas près de cesser, le sujet étant facile et l'approche des lieux aisée ! 
12. - PRÉVOST, Marcel. Nos grandes écoles : Polytechnique. La Nouvelle Société d'Édition, 1931. Concernant ces fluctuations de la mémoire, Francis Eustache, neuropsychologue auteur des «Chemins de la mémoire », coécrit avec Béatrice Desgranges, préfacé par Endel Tulving (éditions du Pommier), répondant à une interview de Nouvel Observateur (numéro 2381, du 24 au 30 juin 2010) nous précise que « les souvenirs sont le reflet de notre personnalité, de notre moi. Et nous les manipulons plus ou moins consciemment pour qu'ils soient en cohérence avec ce que nous pensons être. Ce que nous retenons n'est donc pas anodin.»

13. - ANONYME. Projet de catacombes pour la Ville de Paris, en adaptant à cet usage les carrières qui se trouvent tant dans son enceinte que dans ses environs. À Londres, et se trouve à Paris chez les magasins de nouveautés. M.DCC.LXXXII.

14. - MARTEL, Édouard-Alfred. « Le Monde Souterrain à l'Exposition ». La Nature, 1900, n 1411 (9 juin 1900), p. 22-25.

15. - CORDIER, Daniel. Jean Moulin. La république des Catacombes. Gallimard, 1999.

16. - DELON, Michel. «Des rats dans les catacombes de l'esprit ». Dans Le Mythe en littérature. Essais en hommage à Pierre Brunel (textes réunis par Y. Chevrel et C. Dumoulié). Paris : PUF, collection Écriture, 2000, p. 331-341.

17. - TARDY, Jean-Noël. " Des catacombes à l'insurrection. Signes de reconnaissance, signes de ralliement des sociétés secrètes en France (1821-1851) ». Hypothèses, 2006, Séminaire de l'École des chartes : Visibilité et Invisibilité, p. 45-54. Les sociétés secrètes républicaines de la Monarchie de Juillet ont toujours aimé utiliser la comparaison avec les premiers chrétiens. Il est vrai que parfois le mot et la chose se rencontrent, mais davantage dans la fiction; voir « Les Mohicans de Paris » et "Salvator » d'Alexandre Dumas, ou «La double vie de Théophraste Longuet » et « Le Roi Mystère » de Gaston Leroux.

18. - MAULIN, Oliver. Petit monarque et catacombes. Éditions l'Esprit des péninsules, 2009.

19. - Approximativement au niveau de l'actuel jardin du Luxembourg, et dont il nous reste les expressions un peu tombées en désuétude: "C'est au Diable Vauvert», "Aller au Diable Vauvert » (également « au diable vert »).

20. - Si pour l'espace on assiste a contrario à une dilatation, on connaît pourtant avec extraordinairement plus de précision ce qui est simplement au fond des océans de la terre, que ce qui se trouve sous sa propre ville.

21. - Un peu comme les vestiges de l'enceinte dite de Thiers à Paris, qui sont bien moins abondants que ceux liés à celle de Philippe Auguste.

22. - Groupe Parisien de Recherche sur les Souterrains. Recueil de pièces manuscrites relatives à l'histoire des carrières de Paris au XVII ${ }^{e}$ et XVIII ${ }^{e}$ siècles. Paris, 1986.

23. - D'où l'arrêté préfectoral du 2 novembre 1955 dont avons précédemment eu l'occasion de parler.

24. - GUINI-SKLIAR, Ania. «Les carrières parisiennes aux frontières de la ville et de la campagne ». Histoire urbaine. 2003, vol.2, n8, p. 41-56.

25. - Jean-Paul Rondin, personnage joué par Michel Serrault dans le film Les Gaspards, co-écrit et réalisé par Pierre Tchernia (C 1973).

26. - En guise de simple illustration, sur 327 articles de toutes origines - parus dans des quotidiens, des hebdomadaires, des mensuels ou des revues à périodicité plus grande, aussi bien dans la presse nationale que régionale, voire locale ou d'entreprise, en France comme à l'étranger - entre 1965 et 1997, 59 emploient dans le titre ce terme de "catacombes » pour désigner les anciennes carrières souterraines, soit $18 \%$. Ce pourcentage s'est accru en 1990 pour une simple raison: la diffusion à la télévision, sur une chaîne d'audience nationale, d'un documentaire visant le sensationnel sur la «faune des catacombes ", ce qui généra pour en faire la promotion, de très nombreux articles usant de ce vocabulaire ciblé.

27. - PEYREFITTE, Alain. Rue d'Ulm. Chroniques de la vie normalienne. Fayard, 1998 (édition du bicentenaire), p. 87 (L'école et le fantastique). 
28. - « Politoscopie ». Le Point, 1986, n721 (du 14 juillet), p. 28.

29. - Ce qui donna aussi lieu à un échange épistolaire de confirmation, entre l'impétrant ministériel et le rédacteur de cet article.

30. - Dans un magazine des années 1980, un article traitant uniquement des carrières et catacombes de Paris, montra cette confusion jusque dans son titre : DARMON, Adrian H. « C'est dans les égouts de la capitale qu'ont lieu les dîners en ville ». Il, 1982, numéro d'avril.

31. - Citation de Gaspard de Montfermeil / Philippe Noiret dans le film Les Gaspards, de Pierre Tchernia.

32. - THOMAS, Gilles. «Quand les carrières de la Région parisienne avaient (déjà) une vocation pédagogique ». SAGA information (Bulletin de la Société Amicale des Géologues Amateurs), 2008, n 282 (décembre), p. 9-24.

33. - Voir : THOMAS, Gilles, et al. De la fréquentation des carrières de Paris par les élèves de l'École des Mines lors de la seconde moitié du XIXe siècle, 1850-1900. (Contribution à l'inventaire des inscriptions d'intérêt historique relevées dans les anciennes carrières sous Paris). ENSMP, 1994 ; THOMAS, Gilles, et al. Travaux pratiques de topographie de l'École Centrale des Arts et Manufactures de Paris (ECP) dans les anciennes carrières sous Paris (jusqu'à la veille de la Seconde guerre mondiale, 1900-1937) - Ébauche d'une étude historico-sociologique. ECP, 1995-1996. Quant à l'École Supérieure de Géomètres et Topographes (= SupGéTo), le relevé des traces laissées par les élèves entre 1947 et 1977 est effectué, le dépouillement est en cours et l'étude pas encore finalisée.

34. - On peut lire à ce sujet : THOMAS, Gilles. « Quand les internes allaient en carrières ... avant d'embrasser la leur! (Des carrières souterraines parisiennes à la carrière médicale professionnelle, le parcours de l'Internat passait autrefois par les catacombes de Paris)». L'Internat de Paris (revue de l'Association Amicale des Anciens Internes en Médecine des Hôpitaux de Paris), 2008, n54 (sept. 2008), p. 31-37. Une autre version de ce texte, différente, plus " interne », ou moins censurée (c'est selon), est disponible sur le site du « Plaisir des Dieux »: http://www.leplaisirdesdieux.fr/LePlaisirDesDieux/Histoire/BIBLIO/Articles/ThomasGilles/

ThomasGilles.html. Voir également: THOMAS, Gilles. « Des internes au-dessous de tout, ou quand les «catacombes de Paris" résonnaient de chansons paillardes..." La Lettre de l'Adamap (Association des Amis du Musée de l'AP-HP), 2010, n¹8, 20 juin, p. 41-47 (actes de la XI conférence de l'ADAMAP qui s'est déroulée le vendredi 26 février 2010, en l'hôtel de Miramion : "Salles de garde et folklore médical, une histoire à méditer »).

35. - Une aventure citadine, sans grand risque, limitée à une épopée raisonnable au frisson principalement généré par la transgression d'une frontière que ne franchissait pas la majorité de leurs concitoyens. Le sentiment d'avoir l'impression de faire partie de privilégiés était alors général, chacun ignorant superbement les autres, et se cachant à la moindre lumière fugitive entraperçue sous terre, craignant d'avoir à faire à la police, et ceci déjà même avant l'entrée en vigueur de l'arrêté pris le 2 novembre 1955 interdisant «de pénétrer et circuler dans les anciennes carrières souterraines de la Ville de Paris sans autorisation ». Voir à ce sujet le dossier de THOMAS, Gilles. « Les dits et les non-dits des scouts dans les carrières et catacombes de Paris (ou histoire de la fréquentation des « catacombes » parisiennes circa la Seconde Guerre mondiale jusqu'au lendemain de la promulgation de l'arrêté de 1955 »; à paraître en 2012 dans Signe de piste (le Bulletin des Amis du Signe de Piste). Voir aussi à ce sujet : http://www.fanbobmorane.fr/ MondeSout/DocSiteOfficiel-enPageMondeSouterrain/Cadre\%20et\%20liste.htm.

36. - « Toute révélation d'un secret est la faute de celui qui l'a confié », Jean de La Bruyère (Les Caractères).

37. - DEMARIAUX, Maurice (P47). «Premier prix au Concours Littéraire à l'École des Mine». Revue des Ingénieurs (de l'école des Ponts \& Chaussées, l'école Supérieure d'Aéronautique, l'école Supérieure de Génie Militaire, l'école Supérieure des Mines de Paris, et l'école Supérieure de Métallurgie et d'Industrie des Mines de Nancy), 1950, n² (mars-avril - $3^{\mathrm{e}}$ année), p. 16-18. Ce texte primé commence par : «Il pleut. Par ma fenêtre, je vois un coin de ciel gris. Suzanne ne viendra 
pas cet après-midi. Que faire? Aller aux Catas? Décidément, je ne m'en sens pas le courage aujourd'hui. Il me faudrait revêtir ce complet boueux et ces bottes maculées, et, comme un voleur, courir jusqu'au Val-deGrâce, en rasant les murs. Il me faudrait attendre la nuit pour ressortir de mon trou, afin d'éviter les regards scandalisés de la rue Saint-Jacques... »

38. - CHAUMET, Claude (P47). «L'École des Mines de Paris ». Nouvelles Rive Gauche, 1990, $\mathrm{n}^{\circ}$ 159-160 (juin-juillet 1990), p. 8-9, Dans ce dossier, l'auteur raconte son « Baptême en sous-sol »: «Traditionnellement le baptême de la promotion se déroulait de nuit, début décembre, dans les carrières souterraines appelées improprement catacombes. C'est là que se passaient nos cours de topographie, sous la zone rue Saint-Jacques-Val-de-Grâce, ce qui nous permettait d'avoir une bonne connaissance des lieux. Mais cette année-là, la mienne, les choses ne se sont pas passées comme prévu... »

39. - MOUSSEL, Pierre (P49). «La vie de l'association. Sainte Barbe 1951 à l'École ». Revue des Ingénieurs, 1952, n²5 (janvier): «Au fond, la longue promenade commence, symbole de ces marches que l'ingénieur de fosse entreprend chaque matin jusqu'aux chantiers. Les galeries voûtées s'abaissent, parfois, et s'il n'y a pas de bois cassés qui dépassent, on a toujours une pierre bien placée à sa disposition pour se cogner la tête. Tantôt, l'on barbote allègrement dans la boue, tantôt l'on se glisse astucieusement dans des couloirs étroits, tantôt l'on marche courbé en deux, espérant retrouver bien vite un sol sec et un plafond haut ".

40. - À l'époque de Henri Poincaré (X73), les élèves de Polytechnique formaient un bataillon composé de 4 compagnies réparties en salles d'études : 8 élèves par salle dont un responsable dénommé Chef ou Brigadier.

41. - Cette idée avait été empruntée par Monge à l'École du Génie de Mézières.

42. - Datant de 1872, à l'écart du circuit balisé de leur exercice topographique, on trouve une inscription signée Félix Radominski et Henri Le Chatelier se revendiquant « en vadrouille ».

43. - THOMAS, Gilles. «Les murs de l'Histoire / L'Histoire des murs. Deux autographes méconnus de Henri Poincaré (X-1873) «visibles» à Paris». Bulletin de la SABIX (Société des Amis de la Bibliothèque de l'École polytechnique), octobre 2006, n40, p. 45-55. Texte disponible en ligne : http://www.sabix.org/bulletin/b40/poincare-sabix40.html.

44. - Document conservé à Nancy par le Centre d'Études et de Recherches Henri-Poincaré (plus exactement le Laboratoire de Philosophie et d'Histoire des Sciences - Archives Henri Poincaré), créé à l'Université de Nancy 2 en 1992 (http://poincare.univ-nancy2.fr/Outilsetfonds/? contentId=1474 )

45. - Par décision ministérielle du 10 septembre 1870, M. Jacquot, Ingénieur en chef, fut chargé d'organiser, avec les ingénieurs, agents et ouvriers du service de surveillance des carrières de Paris, un bataillon des mineurs auxiliaires du génie, spécialement préposé à la surveillance et à la garde des carrières sous Paris, ainsi qu'à la pose et à la mise à feu des torpilles aux abords de toutes les porte de la rive droite. Ce corps armé comprenait trois compagnies de mineurs auxiliaires du génie placées sous les ordres des ingénieurs.

46. - Pour en savoir plus, on pourra se reporter à : THOMAS, Gilles et HÉLIAS, Frédéric. « Paris et son enceinte de 1840 : Construction \& Vides souterrains ( $1^{\text {ère }}$ partie) ». L'Arfupéen (Le magazine de l'Association pour la Restauration du Fort d'Uxegney et de la Place d'Épinal), 2007, n54 (septembre), p. 4-9. Suivi de THOMAS, Gilles et HÉLIAS, Frédéric « Paris et son enceinte de 1840 : Construction \& Vides souterrains ( $2^{\mathrm{e}}$ partie) », L'Arfupéen, 2008, n55 (janvier), p. 4-9. Voir également THOMAS, Gilles. «L'enceinte de Paris de 1840 : un géant aux pieds d'argile !» Le Petit Fortillard, 2007, second semestre, $\mathrm{n}^{\circ} 20$, p. 7-36 (rubrique Fortifailleurs).

47. - THOMAS, Gilles. Description iconographique ... des sous-sols de la Région parisienne (ou quand les carrières de Paris portent encore les stigmates de toutes les pièces de théâtre jouées pendant plus de deux cents ans). Séminaire «La Région parisienne: Territoires et Cultures. Descriptions iconographiques du territoire de la région parisienne " (année 2005 - 2006), coorganisé par l'Unité Mémoire de la RATP et les Archives départementales de la Seine Saint-Denis. 
On peut lire également, sur les graffiti(s) historiques et anciens de Paris : COLAS, Christian. Paris graffiti. Les marques secrètes de l'histoire. Parigramme, 2010.

48. - Cette revue en 3 actes "Tout dit: Mine Hurrah » fut jouée le vendredi 7 mars 1925 au Théâtre Albert $1^{\mathrm{er}}$, avec Jeanne Boitel du Théâtre National de l'Odéon, future Sociétaire de la Comédie Française. Il est à noter que la plupart de ces pièces ont un titre en forme de jeu de mot autour de la « Mine ».

49. - Les élèves de l'École polytechnique ont pour habitude de convertir les singuliers des mots se terminant par le son « $O$ » (la lettre, mais écrit aussi « au » ou « eau ») en « al » : des plateaux / un platal ; des bureaux / un bural; etc. Ce procédé a été adopté par les élèves de l'École des Mines, d'où un chamal, des chameaux (animal du désert à deux bosses, image utilisée ici pour parler de la femme), une promal, un apéral, etc.

50. - C'était la fille de la libraire de l'École des Mines.

51. - Confusion courante entre égouts et carrières / catacombes, d'autant plus que les puits d'accès sont obturés par des tampons circulaires de même diamètre que les "plaques d'égout ». Seul un œil attentif peut les distinguer, au moins par l'inscription IDC pour Inspection des Carrières, ou des traces de soudure lorsque cette administration parisienne essaye de les condamner pour décourager les cataphiles de les ouvrir.

52. - Argot d'école désignant la cantine, le repas. Ce nom provient de l'élevage des vers à soie, car c'est dans la magnanerie que sont nourris les cocons. Ce terme est également en usage à l'École Polytechnique.

53. - ESPINASSE, A. Baptême de la promo 44. La Mine noire. 1944, décembre, nº 2, p. 7. L'équivalent de cette ancienne revue interne de l'école, publiée par le Bureau des Élèves, s'appelle de nos jours «Le Vendôme de la Mine» (depuis 1997) ; il y eut aussi «Gisements » (= Le journal de l'École des gens qui font des trous dans la terre de la capitale de la France) entre 1988 et 2000, mais ce fanzine porta également le titre «L'Abatage » entre 1965 et 2001. Chaque année est diffusé un numéro « spécial Ktas », à l'occasion de la Sainte-Barbe et ses festivités associées.

54. - Dans les encadrements particuliers, notons qu'en 1977 c'est une chaîne d'arpenteur rouge qui constituait le cadre; en 1979, le pourtour de la «fresque » fut constitué par la répétition du mot DUR ; l'année d'après, c'est le mot MOU qui sera employé de la même manière. En 1982, c'est une ondulation rouge qui borne le panneau de la promotion; en 1984, c'est une double hélice constituée d'un brin noir et d'un brin rouge.

55. - Au sein de l'X aussi il y avait des «fanas-cata ", ainsi que des «fanas-mili » par exemple. Il convient de noter que le plus célèbre et sérieux quotidien du soir publia un article pour évoquer la passion pour les carrières d'un groupe d'amis "employés par le ministère de la culture, égoutiers du dimanche » : KREMPF, Hervé et MARESTE, Claude. «Les fanas des caves ». Le Monde, 1983, septembre. Ce dossier évoquait en fait ni plus ni moins des cataphiles réunis en une association créée sous les statuts de la Loi du $1^{\text {er }}$ juillet 1901, et aujourd'hui implantée sous l'hôpital Cochin : la SEHDACS.

56. - En 1982, la fanfare des Beaux-Arts se produisit à l'école, et à cette date reprit alors la tradition, abandonnée auparavant, de cette Revue théâtrale de sketches mimant et parodiant les professeurs des Mines.

57. - VIGNOLLE, Jean-Pierre. Les mécanismes de socialisation dans une grande école: étude ethnographique. École des Mines / Université Paris V, mémoire de maîtrise de Sociologie de l'éducation (septembre 1971 ; professeur M. Boudon).

58. - LARGUÈZE, Brigitte. Le bizutage dans la formation des élites : étude d'un rite de passage. Mémoire de DEA. École des Hautes Études en Sciences Sociales, département Anthropologie sociale et Ethnologie, sous la direction de Nicole Belmont, octobre 1990.

59. - Ou à défaut du mot comme aurait dit l'Abbé de l'Attaignant.

60. - Anne Lauvergeon fut adjointe à l'Inspecteur général des carrières de 1985 à 1987. Au cours de la cérémonie à l'École, elle fit remarquer lors de son discours précédant la Petite Revue, que 
pendant son Inspectorat adjoint, elle avait fait fermer de très nombreux accès aux carrières souterraines... donnant ainsi un challenge aux élèves pour qu'ils contournent cet obstacle en vue de satisfaire leur penchant !

61. - Guillaume Gallienne est sociétaire de la Comédie française. Quant à Peggy Bouchet, elle est la première femme à avoir traversé l'Atlantique à la rame en 2000 en 49 jours.

62. - GLOWCZEWSKI, Barbara, et al. La Cité des Cataphiles (mission anthropologique dans les souterrains de Paris). Librairie des Méridiens, 1983 (réédité. ACP, 2008), p. 169.

63. En 1980, une télévision agrémente le tableau dessiné en souvenir du baptême; la marraine était alors la speakerine Michèle Maillet.

64. Extrait d'un texte écrit par Lou Malévit, présentant le trinôme d'artistes peintres parisiens qui prirent comme surnom l'acronyme VLP pour « Vive la peinture ».

65. - NEIMON, Delphine. L'art dans les carrières de Paris. Séminaire «La Région parisienne: Territoires et Cultures. Descriptions iconographiques du territoire de la région parisienne » (année 2005 - 2006), co-organisé par l'Unité Mémoire de la RATP et les Archives départementales de la Seine Saint-Denis.

66. - Un artiste amateur ne poursuivit pas dans ce domaine d'expression, bien qu'il signât sous Paris quelques œuvres majeures comme Obstruction 82 (toujours visible), Entrave 83 et Percé 84, aujourd'hui disparues.

67. - Fin 2008, cette Source a fait l'objet d'une évocation illustrée dans le catalogue de l'exposition consacrée à la postérité de Ingres, qui fut d'abord présentée à Québec puis se poursuivit à Montauban: SALMON, Dimitri. Ingres et les modernes, catalogue de l'exposition, co-édité par la RMN. Somogy éditions d'art, décembre 2008, p. 198 (fig.167).

68. - CHABERT, Jacques. «Le combat des cataphiles contre les cataclastes ». Spelunca, 1985, n 19 (juil.-sept.), p. VIII

69. - Citons en 1993, un personnage emblématique issu des "Chroniques de la Lune Noire » (bande dessinée de Ledroit et Froideval) ainsi que le fantôme logo de Ghostbusters; en 1994, Roger Rabbit et son amour Jessica; en 1999, Notre-Dame et le Louvre; en 2000, un vitrail à l'effigie de Sainte-Barbe ; en 2002, Corto Maltés ; en 2005, le Sacré-Cœur de Montmartre vu depuis le manège rendu célèbre par Amélie Poulain.

70. - ARCHER, Caroline. Paris Underground. Mark Batty publisher, juillet 2005. Le titre initialement prévu était Parisian Art Underground.

71. - La Maison de la Mine et des Ponts \& Chaussées (autrefois dénommée "Meuh de Meuh », pour MdM). Certains voudront bien y voir tout un symbole dans la représentation d'une vue aérienne sous le ciel limité et clos des carrières sous Paris. Mais une autre information n'est pas dénuée d'humour: la marraine de promotion fut Ségolène Royale, qui deux années plus tard mena une croisade anti-bizutage (article 225-16-1 de la loi du 17 juin 1998). Il est à noter que son nom écrit en tout petit a été très rapidement effacé du support mural.

72. - Cet autre "Mucha », dû au pinceau du même "Mineur-artiste ", ayant été réalisé sur un des murs de l'actuelle salle des boîtes aux lettres des élèves de l'École des Mines, il est beaucoup plus facile d'aller l'admirer.

73. - HOTTIN, Christian. «Fresques des salles de garde des hôpitaux parisiens - artistes et médecins, médecins artistes ». Labyrinthe, hiver 2002-2003, n¹4, p. 75-100.

74. - THOMAS, Gilles. "Exposition Universelle Internationale de Paris (Quand les sous-sols parisiens regorgeaient de charbon et de minerai aurifère. Révélations sur des gisements miniers exploités en 1900 ! "SAGA information (Bulletin de la Société Amicale des Géologues Amateurs), 2010, n²98 (juin à août), p. 5-21.

75. - La seconde étant le Monde Souterrain, présentant des reconstitutions de découvertes archéologiques majeures : tombeau d'Agamemnon, Mastaba de Ti, pagodes chinoises, gouffre de Padirac, etc. 
76. - Aux Pays-Bas, il est toujours possible de visiter la mine de charbon de Steenkolenmijn reconstituée dans une carrière de calcaire (http://www.steenkolenmijn.nl), qui célèbrera en 2012 les 95 ans de son ouverture.

\section{RÉSUMÉS}

Il existe dans Paris, au sens géologique du terme, c'est à dire sous la ville, un espace figé qui a gardé les traces de toutes les pièces du théâtre de l'Histoire qui s'y sont jouées depuis la fin du $\mathrm{XVIII}^{\mathrm{e}}$ siècle : les catacombes, ou plus exactement les anciennes carrières souterraines de la Ville de Paris. Dans ce Paris sous Paris, l'Histoire de France côtoie les petites histoires estudiantines puisque de Grandes Écoles parisiennes y organisèrent des travaux pratiques de topographie, et de nos jours une tradition théâtralisée persiste : le baptême de chaque nouvelle promotion de l'École des Mines « ParisTech».

There is in Paris, in the geologic sense of the term, that is under the city, a motionless space keeping tracks of all the parts played by history since the end of the XVIII ${ }^{\text {th }}$ century: catacombs, or more precisely former Parisian subterranean quarries. In this Paris right under Paris, History of France goes alongside student life anecdoctes because some Parisian post gradutate school organized topography classes there, and till nowadays a theatralized tradition persists: the naming of every new promotion of the École des Mines (French engineering school) " ParisTech

". (traduction Vivianne Perret)

\section{INDEX}

Keywords : Engineering schools, old underground limestone quarries / catacombs, topography classes, students' wall inscriptions, school of mines, naming of new promotion

Mots-clés : Grandes-Écoles, anciennes carrières souterraines / catacombes, cours de topographie, graffitis estudiantins, tradition picturale

\section{AUTEUR}

\section{GILLES THOMAS}

fonctionnaire à la Ville de Paris gilles.thomas@paris.fr 